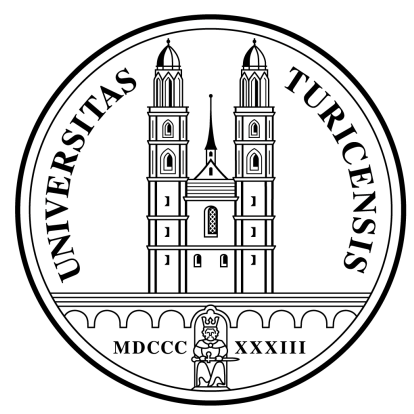

Institute for Empirical Research in Economics

University of Zurich

Working Paper Series

ISSN 1424-0459

Published in: American Economic Review, 2000, Vol. 90 (4); 980-994

Working Paper No. 10

Cooperation and Punishment in Public Goods

Experiments

Ernst Fehr and Simon Gächter

June 1999 


\title{
Cooperation and Punishment in Public
}

\section{Goods Experiments*}

\author{
Ernst Fehr and Simon Gächter
}

\author{
University of Zurich \\ Institute for Empirical Research in Economics \\ Blümlisalpstrasse 10 \\ $\mathrm{CH}-8006$ Zurich \\ e-mail: efehr@iew.unizh.ch; gaechter@iew.unizh.ch \\ http://www.unizh.ch/iew/grp/fehr/index.html
}

Working Paper No. 10

June 1999

\footnotetext{
* This paper is part of the EU-TMR Research Network ENDEAR (FMRX-CT98-0238). Support from the Swiss National Science Foundation under project number 1214-051000.97 and from the MacArthur Foundation Network on Economic Environments and the Evolution of Individual Preferences and Social Norms is gratefully acknowledged. We received valuable comments by seminar participants at the MacArthur-Foundation Meeting in Stanford, the Workshop in Experimental Economics in Berlin, the ASSA-Meetings in New Orleans and New York, the IAREP conference in Valencia, the Econometric Society European Meeting in Toulouse, the ESA meeting in Mannheim, the European Economic Association conference in Berlin and by seminar participants at Basel, Bern, Bonn, Dortmund, Lausanne, Linz, Munich, Pittsburgh, Tilburg and St. Gallen, and by Richard Beil, Samuel Bowles, Rob Boyd, Martin Brown, Robyn Dawes, Armin Falk, Urs Fischbacher, Herb Gintis, John Kagel, Georg Kirchsteiger, David Laibson, George Loewenstein, Tanga McDaniel, John Miller, Paul Romer, and Klaus Schmidt. We are particularly grateful to Urs Fischbacher who did the programming.
} 


\title{
Cooperation and Punishment in Public Goods Experiments
}

\begin{abstract}
This paper provides evidence that free riders are heavily punished even if punishment is costly and does not provide any material benefits for the punisher. The more free riders negatively deviate from the group standard the more they are punished. As a consequence, the existence of an opportunity for costly punishment causes a large increase in cooperation levels because potential free riders face a credible threat. We show, in particular, that in the presence of a costly punishment opportunity almost complete cooperation can be achieved and maintained although, under the standard assumptions of rationality and selfishness, there should be no cooperation at all.

We also show that free riding causes strong negative emotions among cooperators. The intensity of these emotions is the stronger the more the free riders deviate from the group standard. Our results provide, therefore, support for the hypothesis that emotions are guarantors of credible threats.
\end{abstract}

Keywords: Voluntary cooperation, public good, punishment, emotions, social norms, experiments JEL-classification: D63, D64, H41, C91, C92 


\section{Introduction}

During the oil crisis in 1979 the Carter administration implemented a system of fuel allocation and price controls that led to long queues at gas stations. Sometimes drivers tried to avoid the costs of waiting by butting into line. As a result of these attempts many motorists were involved in "fistfights and shouting matches with one another. One motorist was shot and killed for butting into line" (Frank, 1994, p. 31). This example neatly communicates a main message of this paper. In situations with free riding incentives people frequently do not passively accept the free riding of others. Instead, when they have the opportunity to punish free riders, they do so even if this is costly for them and even if they cannot expect future benefits from their punishment activities. ${ }^{1}$ The beauty of the above queuing example is that queuing is likely to be a one-shot phenomenon. A motorist who knocks down or even shoots a driver who is butting into line is not driven by the expectation of future rewards. It seems much more likely that the source of the punishment is the anger that is caused by the noncooperative behavior of the other driver. Examples like this led Hirshleifer (1987) and Frank (1988) to the hypothesis that emotions are guarantors of credible threats.

A main purpose of this paper is to show experimentally that the above episode is not just a single event but that free riding generally causes very strong negative emotions among cooperators and that there is a widespread willingness to punish the free riders. Our results indicate that this holds true even if punishment is costly and does not provide any material benefits for the punisher. In addition, we provide evidence that free riders are punished the more heavily the more they deviate from the cooperation levels of the cooperators. Potential free riders, therefore, can avoid or at least reduce punishment by increasing their cooperation levels. This, in turn, suggests that in the presence of punishment opportunities there will be less free riding. Testing this conjecture is the other major aim of our paper.

For this purpose we conducted a public good experiment with and without punishment opportunities. In the treatment without punishment opportunities complete free riding is a dominant strategy. In the treatment with punishment opportunities punishing is costly for the punisher. Therefore, purely selfish subjects will never punish in a one-shot context. This means that if there are only selfish subjects, as is commonly assumed in economics, the treatment with punishment opportunities should generate the same contribution behavior as the treatment without such

\footnotetext{
${ }^{1}$ Note that the maintenance of a well-ordered queue constitutes a public good because all people benefit from the queue and everybody has an incentive to outpace the others. In the absence of punishments a person is always better off when reducing waiting time given that others are waiting in the queue. If the queue dissolves and everybody is trying to get served first, the best action for everybody is to also trying to get served first. If others try to get served early while I do not, I will have a waiting time that is far above the average waiting time. However, if everybody tries to get served first the result will be chaos and nobody will, on average, get served earlier. In addition, the unpleasant experience of waiting under chaotic circumstances makes everybody worse off relative to waiting in a well-ordered queue.
} 
opportunities. The reason is, of course, that the presence of punishment opportunities is irrelevant for the contribution behavior if there is no punishment. In sharp contrast to this prediction we observe vastly different contributions in the two conditions. In the no-punishment condition contributions converge to very low levels, i.e., between 53 and 75 percent of the subjects free ride completely in the final period while the remaining subjects contribute only little. In the punishment condition, however, average contribution rates between 50 and 95 percent of the endowment can be maintained. If subjects in the punishment condition have the opportunity to implicitly coordinate on a common group standard their contributions converge to almost full cooperation: In the final period of this treatment 82.5 percent of the subjects contribute the whole endowment although the standard economic model predicts no cooperation at all. ${ }^{2}$

In our view the introductory example and the strong regularities observed in our experiments suggest that emotion-based punishment of free riding is of general importance. It is likely to play a role in many social interactions like, e.g., industrial disputes, in team production settings or, quite generally, in the maintenance of social norms. If, for example, striking workers ostracize strike breakers (Francis 1985) or if, under a piece rate system, the violators of productions quotas are punished by those who stick to the norm (Roethlisberger and Dickson 1947, Whyte 1955), it seems likely that similar forces are at work as in our experiments. ${ }^{3}$ Note that in our experiments the description of the public good and the option to punish is framed in completely neutral terms. ${ }^{4}$ In reality, however, free riding is frequently described in rather value laden terms. Strike breakers, e.g., are called 'scabs' and during World War I British men who did not volunteer for the army were called 'wimps'. The very existence and frequent use of such value laden terms suggests that emotions are involved and can be elicited by these terms. In view of the fact that free riding is described by such expressions emotion-based punishment may even be more important in reality than in our experiments.

To our knowledge there is no other work that shows the widespread existence of a willingness to punish free riding when it is costly and does not provide private material benefits for the punisher. Nor do we know of evidence that relates this willingness to punish to the underlying negative emotions. Our work is most akin to the seminal paper by Ostrom, Walker and Gardner (1992). These authors also allowed for costly punishment. Their experiments were mainly designed

\footnotetext{
${ }^{2}$ We define the standard model as characterized by the following assumptions: (i) All individuals only aim at maximizing their own material payoff. (ii) All individuals are sequentially rational, i.e., capable of performing the relevant backwards induction.

${ }^{3}$ Francis' $(1985$, p. 269) description of social ostracism in the communities of the British miners provides a particularly vivid example. During the 1984 strike of the miners, which lasted for several months, he observed the following: "To isolate those who supported the 'scab union', cinemas and shops were boycotted, there were expulsions from football teams, bands and choirs and 'scabs' were compelled to sing on their own in their chapel services. 'Scabs' witnessed their own 'death' in communities which no longer accepted them".

${ }^{4}$ The public good is called 'project' and punishing occurs by 'assigning points' (see the instructions in the appendix).
} 
for the purpose of understanding the impact of punishment opportunities in a repeated common pool resource game and the interaction of the punishment opportunity with ex ante face to face communication. In their experiments the group composition remained constant over time, i.e., in each period the same subjects interacted with each other. Moreover, the number of periods was unknown to the subjects. In addition, subjects could develop an individual reputation based on their history of cooperation decisions. The results show that subjects indeed based their punishment decisions on the reputation of the other subjects. Since the same group of subjects interacts for an ex ante unknown number of periods and since individual reputation formation was possible in these experiments there were material incentives for cooperation and for punishment. To rule out such material incentives we eliminated all possibilities for individual reputation formation and implemented treatment conditions with an ex ante known finite horizon. In addition, we also had treatments in which the group composition changed randomly from period to period so that the probability of meeting the same subject in future periods was very low. In one of our treatments we even ensured that the probability of meeting the same subjects in the future is zero.

Our work is also related to the interesting study of Hirshleifer and Rasmusen (1989) who show that, if there are opportunities for ostracizing non-cooperators, rational egoists can maintain cooperation for T-1 periods in a T-period Prisoner's Dilemma. In this model ostracizing noncooperators is part of a subgame perfect equilibrium and, hence, rational for selfish group members. This feature distinguishes the above model from our experimental set-up. In our experiments cooperation or punishment can never be part of a subgame perfect equilibrium if rationality and selfishness are common knowledge. We deliberately designed our experiments in this way to examine whether people punish free-riders even if it is against their material self-interest.

The remainder of this paper is organized as follows: In Section II we present our experimental design in more detail. In Section III we shortly present the predictions of the standard economic model and contrast them with the implications of our alternative behavioral assumptions. In Section IV the major behavioral regularities of our experiments are presented. Section V interprets these regularities in the light of our behavioral assumptions and provides evidence on the pattern of emotional responses to free riding. Finally, Section VI summarizes the paper and provides concluding remarks.

\section{The Experimental Design}

Since we hypothesize that there is a willingness to punish free riding we have to set up a public good experiment with punishment opportunities. Moreover, since we further hypothesize that the willingness to punish is not merely a strategic investment into the deterrence of free riding in the 
future we have to implement a design which rules out future benefits from present punishment activities. If we observe in this environment that free riders are punished we have evidence in favor of the above hypothesis.

\section{A. Basic Design}

Our overall design consists of a public good experiment with four treatment conditions (see Table 1). There is a 'Stranger'-treatment with and without punishment opportunities and a 'Partner'-treatment with and without punishment opportunities. In the Partner-treatments the same group of $n=4$ subjects plays a finitely repeated public good game for ten periods, that is, the group composition does not change across periods. For each Partner-session we planned six groups of size $n=4 .^{5}$ In contrast, in the Stranger-conditions the total number of participants in an experimental session, $N=24$, is randomly partitioned into smaller groups of size $n=4$ in each of the ten periods. Thus, the group composition in the 'Stranger'-treatments is randomly changed from period to period. The treatments without punishment opportunities serve as a control for the treatment with punishment opportunities. In a given session of the Stranger-treatment the same $N$ subjects play ten periods in the punishment and ten periods in the no-punishment condition. Similarly, in a session of the Partner-treatment all groups of size $n$ play the punishment and the no-punishment condition. This has the advantage that, in addition to across-subject comparisons, we can make within-subject comparisons of cooperation levels which have much more statistical power. In Sessions $1-3$ we implemented Stranger-conditions while in Sessions 4 and 5 we implemented Partner-conditions. In Sessions 1 and 2 subjects play first ten periods in the punishment condition and then ten periods in the no-punishment condition. To test for spillover effects across conditions the no-punishment condition is conducted first in Session 3. In Session 4, which implemented Partner-conditions, we start with the punishment condition while Session 5 begins with the no-punishment condition.

Note that in the Partner-treatment the probability of being rematched with the same three people in the next period is 100 percent while in the Stranger-treatment it is less than 0.05 percent. Moreover, even if a subject is rematched in the next period with one of the previous group members, our anonymity conditions ensure that the subject does not know this. Thus, due to the very low probability of being rematched with the same subjects in future periods and due to our anonymity conditions the Stranger-treatment comes close to pure one-shot interactions. ${ }^{6}$ However, since the probability of meeting the same people in the future is not exactly zero one might argue

\footnotetext{
${ }^{5}$ Unfortunately, in one Partner-session only 16 subjects showed up so that we had only 4 groups of size $n=4$.

${ }^{6}$ By the term one-shot we do not mean that subjects play the public good game only once. We mean, instead, that subjects do not have future interactions with the same group members. Therefore, repetitions of the game preserve the one-shot character as long as the probability of future interactions with the same subjects is negligible or zero, respectively.
} 
that the Stranger-treatment is not truly one-shot. To examine the relevance of this objection we have conducted robustness tests by implementing a so-called Perfect Stranger-treatment. In this treatment we ensure that each subject meets any of the other $N-1$ subjects exactly once, i.e., the probability of future interactions with the same subject is zero. The results of this robustness test are presented in section IV.E.

Table 1 - Treatment Conditions

\begin{tabular}{ccc}
\hline \hline & $\begin{array}{c}\text { Stranger-treatment } \\
\text { Random group composition } \\
\text { in each period } \\
\text { (Session 1, 2, 3) }\end{array}$ & $\begin{array}{c}\text { Partner-treatment } \\
\text { Group composition constant } \\
\text { across periods } \\
\text { (Session 4 and 5) }\end{array}$ \\
\hline $\begin{array}{c}\text { Without Punishment } \\
\text { (ten periods) } \\
\text { With punishment } \\
\text { (ten periods) }\end{array}$ & 18 groups of size $n$ & 10 groups of size $n$ \\
\hline \hline
\end{tabular}

\section{B. Payoffs}

In the following we first describe the payoffs in the treatments without punishment. In each period each of the $n$ subjects in a group receives an endowment of $y$ tokens. A subject can either keep these tokens for himself or invest $g_{i}$ tokens $\left(0 \leq g_{i} \leq y\right)$ into a project. The decisions about $g_{i}$ are made simultaneously. The monetary payoff for each subject $i$ in the group is given by

$$
\pi_{i}^{1}=y-g_{i}+a{ }_{j=1}^{n} g_{j}, \quad 0<a<1<n a
$$

in each period. The total payoff from the no-punishment condition is the sum of the period-payoffs, as given in (1), over all ten periods. Note that (1) implies that full free-riding $\left(g_{i}=0\right)$ is a dominant strategy in the stage game. This follows from $\partial \pi_{i}^{1} / \partial g_{i}=-1+a<0$. However, the aggregate payoff ${ }^{n} \pi_{i}^{1}$ is maximized if each group member fully cooperates $\left(g_{i}=y\right)$ because $i=1$

$\partial_{i=1}^{n} \pi_{i}^{l} / \partial g_{i}=-1+n a>0$.

The major difference between the no-punishment and the punishment conditions is the addition of a second decision stage after the simultaneous contribution decision in each period. At the second stage subjects are given the opportunity to simultaneously punish each other after they are informed about the individual contributions of the other group members. Group member $j$ can 
punish group member $i$ by assigning so-called punishment points $p_{j}^{i}$ to $i$. $^{7}$ For each punishment point assigned to $i$ the first stage payoff of $i, \pi_{i}^{l}$, is reduced by ten percent. However, the first stage payoff of subject $i$ can never be reduced below zero. Therefore, the number of payoff-effective punishment points imposed on subject $i, P^{i}$, is given by $P^{i}=\min \left(\underset{j \neq i}{p_{j}^{i}}, 10\right)$. The cost of punishment for subject $i$ from punishing other subjects is given by $\underset{j \neq i}{c}\left(p_{i}^{j}\right)$ where $c\left(p_{i}^{j}\right)$ is strictly increasing in $p_{i}^{j}$. The pecuniary payoff of subject $i, \pi_{i}$, from both stages of the punishment treatment can, therefore, be written as

$$
\pi_{i}=\pi_{i}^{l}\left[1-(1 / 10) P^{i}\right]-\underset{j \neq i}{c} c\left(p_{i}^{j}\right)
$$

The total payoff from the punishment condition is the sum of the period-payoffs, as given in (2), over all ten periods.

\section{Parameters and Information Conditions}

The experiment is conducted in a computerized laboratory where subjects anonymously interact with each other. No subject is ever informed about the identity of the other group members. In all treatment conditions the endowment is given by $y=20$, groups are of size $n=4$, the marginal payoff of the public good is fixed at $a=0.4$ and the number of participants in a session is $N=24 .{ }^{8}$ Table 2 shows the feasible punishment levels and the associated cost for the punisher. In each period subject $i$ can assign up to ten punishment points $p_{i}^{j}$ to each group member $j, j=1, \ldots, 4, j \neq i$.

Table 2 - Punishment levels and associated costs for the punishing subject

\begin{tabular}{llllllllllll}
\hline \hline punishment points $\boldsymbol{p}_{\boldsymbol{i}}^{j}$ & $\mathbf{0}$ & $\mathbf{1}$ & $\mathbf{2}$ & $\mathbf{3}$ & $\mathbf{4}$ & $\mathbf{5}$ & $\mathbf{6}$ & $\mathbf{7}$ & $\mathbf{8}$ & $\mathbf{9}$ & $\mathbf{1 0}$ \\
$\operatorname{costs}$ of punishment $c\left(p_{i}^{j}\right)$ & 0 & 1 & 2 & 4 & 6 & 9 & 12 & 16 & 20 & 25 & 30 \\
\hline \hline
\end{tabular}

In all treatment conditions subjects are publicly informed that the condition lasts exactly for ten periods. When subjects play the first treatment condition in a session they do not know that a session consists of two conditions. After period ten of the first treatment condition in a session they

\footnotetext{
${ }^{7}$ In the instructions we did of course use a neutral language to describe the punishment option. In the language of the instructions, subjects could assign 'points' to the other group members.

${ }^{8}$ An exception is Session 4 where only $N=16$ subjects showed up.
} 
are informed that there will be a "new experiment" and that this experiment will again last exactly for ten periods. They are also informed that the experiment will then be definitely finished. ${ }^{9}$

In the no-punishment conditions the payoff function (1) and the parameter values of $y, n, N$ and $a$ are common knowledge. At the end of each period subjects in each group are informed about the total contribution $\Sigma g_{j}$ to the project in their group.

In the punishment conditions the payoff function (2) and Table 2 are, in addition to $y, n, N$ and $a$, common knowledge. Furthermore, after the contribution stage subjects are also informed about the whole vector of individual contributions in their group. ${ }^{10}$ To prevent the possibility of individual reputation formation across periods in the Partner-treatment each subjects' own contribution is always listed in the first column of his computer screen and the remaining three subjects' contributions are randomly listed in the second, third or fourth column, respectively. ${ }^{11}$ Thus, subject $i$ does not have the information to construct a link between individual contributions of subject $j$ across periods. Therefore, subject $j$ cannot develop a reputation for a particular individual contribution behavior. This design feature also rules out that $i$ punishes $j$ in period $t$ for contribution decisions taken in period $t^{\prime}<t$. Subjects are never informed about the individual punishment activities of the other group members. They only know their own punishment activities and the aggregate punishments imposed on them by the other group members.

\section{Predictions}

To have an unambiguous reference prediction it is useful to shortly state the implications of the standard approach to the public good games of Table 1. If all subjects are rational money maximizers, and if this is common knowledge, the subgame perfect equilibrium prediction with

\footnotetext{
${ }^{9}$ This procedure has the advantage that the first treatment condition in a session is definitely unaffected by the subsequent treatment. Thus, the comparison of punishment and no-punishment conditions that are played first is unaffected by any spillover effects. In addition, by comparing the behavior in a condition that is played first in a session with the behavior in the same condition when it is played second in a session we can explicitly study spillover effects.

${ }^{10}$ Note that the information feedback after the contribution decisions is slightly different in the no-punishment and punishment condition because in the former subjects are only informed about the total contribution of the group and their own contribution. There is evidence that additional information about the whole contribution vector in the nopunishment condition slightly decreases cooperation levels (Croson 1995, Andreoni 1995) or leaves them unaffected (Weimann 1994). In addition, we also ran two independent sessions in the no-punishment condition (not reported in this paper) in which subjects were informed about the whole contribution vector. Contributions are the same compared to our main sessions where subjects were only informed about the average contribution in the group. Taken together, these facts suggest that a comparison between the punishment and no-punishment condition slightly underestimates, if anything, the impact of punishment opportunities.

${ }^{11}$ In the Stranger-treatments individual reputation formation is ruled out by the random determination of the group composition in each period and the fact that subjects do not know with whom they are matched. In the Partner-treatment without punishment, reputation formation is ruled out by not informing subjects about individual contributions of the other players.
} 
regard to $g_{i}$ for each of the four cells in Table 1 is identical: In all four treatment conditions all subjects will contribute nothing to the public good in all periods. This is most transparent in the Stranger-treatment without punishment. This condition consists just of a sequence of ten (almost pure) one-shot games. In each one-shot game players' dominant strategy is to free ride fully. Applying the familiar backward induction argument to the Partner-treatment without punishment gives us the same prediction.

In the Stranger-treatment with punishment the situation is slightly more complicated because each one-shot game now consists of two stages. It is clear that a rational money maximizer will never punish at the second stage because this is costly for him. Since rational players will recognize that nobody will punish at the second stage the existence of the punishment stage does not change the behavioral incentives at the first stage relative to the Stranger-treatment without punishment. As a consequence, everybody will choose $g_{i}=0$ at stage one. For the same reasons as in the Strangertreatment rational subjects in the Partner-treatment with punishment will choose $g_{i}=0$ and $p_{i}^{j}=0$ for all $j$ in the final period. By applying the familiar backward induction argument we arrive, thus, at the prediction that $g_{i}=0$ and $p_{i}^{j}=0$ for all $j$ will be chosen by all subjects in all periods of the Partner-treatment with punishment.

There is already a lot of evidence for public good games like our no-punishment condition. For these games it is well known that cooperation strongly deteriorates over time and reaches rather low levels in the final period (Dawes and Thaler 1988, Ledyard 1995). In a recent meta-study Fehr and Schmidt (forthcoming) surveyed 12 different public good experiments without punishment where full free riding is a dominant strategy in the stage game. During the first periods of these experiments average and median contribution levels varied between 40 and 60 percent of the endowment. However, in the final period 73 percent of all individuals $(N=1042)$ chose $g_{i}=0$ and many of the remaining players chose $g_{i}$ close to zero. In view of these facts there can be little doubt that in the no-punishment condition subjects are not able to achieve stable cooperation. Therefore, the main objective of our experiment is to see whether subjects are capable of achieving and maintaining cooperation in the punishment condition.

In our view, the fact that at the beginning of the no-punishment condition one regularly observes relatively high cooperation rates, suggests that not all people are driven by pure selfinterest. We conjecture that, in addition to purely selfish subjects, there is a nonnegligible number of subjects who are (i) conditionally cooperative and (ii) willing to engage in the costly punishment of free riders. This conjecture is based on evidence from many other experimental games. Bilateral trust- or gift exchange games (Berg, Dickhaut and McCabe 1995; Fehr and Falk 1999) indicate that many subjects are conditionally cooperative, i.e., they are willing to cooperate to some extent if others cooperate, too. Recently, Croson (1998) and Fischbacher, Gächter and Fehr (1998) have shown that many subjects also behave conditionally cooperative in $n$-person public good games. 
Bilateral ultimatum and contract enforcement games (Camerer and Thaler 1995, Güth and Tietz 1990, Roth 1995, Fehr, Gächter and Kirchsteiger 1997) indicate that many subjects are willing to punish behavior that is perceived as unfair. In our public goods context fairness issues are likely to play a prominent role, too. We believe, in particular, that subjects strongly dislike being the 'sucker', i.e., being those who cooperate while other group members free ride. This aversion against being the 'sucker' might well trigger a willingness to punish free riders.

In view of the evidence mentioned above it is reasonable to assume that there is a mix of selfish, conditionally cooperative and punishing subjects in our experiments. The main question then is, under which conditions the interaction between these types generates stable cooperation. What we apparently know already is that in the no-punishment condition stable cooperation is in general not possible. The reason for implementing a punishment condition is that it might enable punishing types to establish and maintain cooperation. Note that in the no-punishment condition punishing types have no direct means to discipline the selfish types. All they can do, in response to the anticipated defection of selfish types, is to defect also. Yet, in the punishment condition they can discipline the selfish types directly by punishing free riding. Moreover, if potential free riders are deterred by the punishment threat, the conditional cooperators also have a reason to cooperate. Thus, it could be that in the no-punishment condition the selfish types induce the other types to defect also, while in the punishment condition the disciplining of the selfish types by the punishing types induces all subjects to cooperate. Recently, Fehr and Schmidt (forthcoming) provided a more rigorous theoretical basis for this conjecture. In their model conditionally cooperative and punishing behavior is driven by people's fairness motives. They show that in games like our no-punishment condition a majority of fair-minded subjects cannot obtain cooperation in equilibrium if there is a minority of selfish subjects. They also show that even a minority of fair-minded (i.e., punishing) subjects can enforce an equilibrium with full cooperation in the punishment condition. ${ }^{12}$

Both in the Stranger- and in the Partner-treatment with punishment there are no explicit coordination opportunities. It is, therefore, difficult for subjects to form correct expectations about the behavior of other group members and to develop a common contribution standard. This is particularly transparent in the Stranger-treatment where subjects face new group members in each period. Yet, in the Partner-treatment subjects experience a common group history which provides a better basis for the formation of accurate beliefs about each others' behavior than in the Strangertreatment. In the Partner-treatment with punishment it is, therefore, more likely that a behavioral norm that differs from full free riding will evolve.

\footnotetext{
${ }^{12}$ Heckathorn (1996) also examines a public good model with punishment opportunities. His simulations, which allow for different strategies (types), indicate the importance of punishing types for cooperation.
} 


\section{Experimental Results}

In total, we have observations from 112 subjects. Each subject participated only in one of the five experimental sessions. All sessions were held in January and February 1996. Subjects were students from many different fields (except economics). They were recruited via letters which were mailed to their private addresses. With this procedure we wanted to maximize the chances that subjects do not

know each other. ${ }^{13}$ An experimental session lasted about two hours and subjects earned on average $\$ 34$ - including a show-up fee of \$ 12.50 .

\section{A. The Impact of Punishment Opportunities in the Stranger-Treatment}

If subjects believe that in the presence of punishment opportunities free riding faces no credible threat we should observe no differences in contributions across treatments. In sharp contrast to this prediction we can report the following result:

RESULT 1: The existence of punishment opportunities causes a large rise in the average contribution level in the Stranger-treatment.

Support for Result 1 is presented in Table 3. In columns two and three of Table 3 we report the mean contribution over all ten periods in the three sessions of the Stranger-treatment. The table reveals that in the punishment condition subjects contribute between two and four times more than in the no-punishment condition. A nonparametric Wilcoxon matched pairs test shows that this difference in contributions is significant at all conventional significance levels $(\mathrm{p}<0.0001)$. This result clearly refutes the hypothesis of the standard approach that punishment opportunities are behaviorally irrelevant at the contribution stage of the game.

\footnotetext{
${ }^{13}$ Other recruitment methods like, e.g., public recruitment in classrooms have a much higher probability that groups of subjects who know each other participate in a particular session.
} 
Table 3 - Mean contributions in the Stranger-treatment

\begin{tabular}{ccccc}
\hline \hline & \multicolumn{2}{c}{$\begin{array}{c}\text { mean contribution in } \\
\text { all periods }\end{array}$} & \multicolumn{2}{c}{$\begin{array}{c}\text { mean contribution in } \\
\text { the final periods }\end{array}$} \\
\hline Sessions & $\begin{array}{c}\text { without } \\
\text { punishment } \\
\text { opportunity }\end{array}$ & $\begin{array}{c}\text { with } \\
\text { punishment } \\
\text { opportunity }\end{array}$ & $\begin{array}{c}\text { without } \\
\text { punishment } \\
\text { opportunity }\end{array}$ & $\begin{array}{c}\text { with } \\
\text { punishment } \\
\text { opportunity }\end{array}$ \\
\hline 1 & 2.7 & 10.9 & 1.3 & 9.8 \\
& $(5.2)$ & $(6.1)$ & $(4.3)$ & $(6.8)$ \\
2 & 4.0 & 12.9 & 2.3 & 14.3 \\
& $(5.7)$ & $(6.4)$ & $(4.3)$ & $(5.0)$ \\
3 & 4.5 & 10.7 & 2.0 & 13.1 \\
& $(6.0)$ & $(4.9)$ & $(3.8)$ & $(4.0)$ \\
\hline mean & $\mathbf{3 . 7}$ & $\mathbf{1 1 . 5}$ & $\mathbf{1 . 9}$ & $\mathbf{1 2 . 3}$ \\
& $\mathbf{( 5 . 7 )}$ & $\mathbf{( 5 . 9 )}$ & $\mathbf{( 4 . 1 )}$ & $\mathbf{( 5 . 6 )}$ \\
\hline \hline
\end{tabular}

Note: Numbers in parentheses are standard deviations. Participants of Sessions 1 and 2 first played the treatment with punishment opportunities and then the one without such opportunities. Participants of Session 3 played in the reverse order.

Next we turn to the evolution of contributions over time. Remember that one of the most robust behavioral regularities in sequences of one-shot public good games, like our Stranger-treatment without punishment, is that contributions drop over time to very low levels. Our next result provides information whether punishment opportunities can prevent such a fall in contributions:

RESULT 2: In the no-punishment condition of the Stranger-treatment average contributions converge close to full free riding over time. In contrast, in the punishment condition average contributions do not decrease or even increase over time.

Support for Result 2 comes from Table 3 and Figures 1a and 1b. Columns four and five of Table 3 show that, in each session, in the final period of the no-punishment condition average contributions vary between 1.3 and 2.3 tokens. ${ }^{14}$ In contrast, in the punishment condition average contributions vary between 9.8 and 14.3 tokens in period ten. Thus, in the final period of the punishment condition the average contribution is between 6 and 7.5 times higher than in the no-punishment condition. Moreover, a comparison of column three with column five of Table 3 reveals that in the

\footnotetext{
${ }^{14}$ Note that in the following the term 'final period' is always used to indicate the last period in a given treatment condition and not only period 20 in a given session. Thus, for example, in Figure 1a the tenth period is the final period of the punishment condition.
} 
punishment condition the average contribution in period ten is higher or roughly the same as in all periods.

Figure 1a: Average contributions over time in the Stranger-treatment (Sessions 1 and 2)

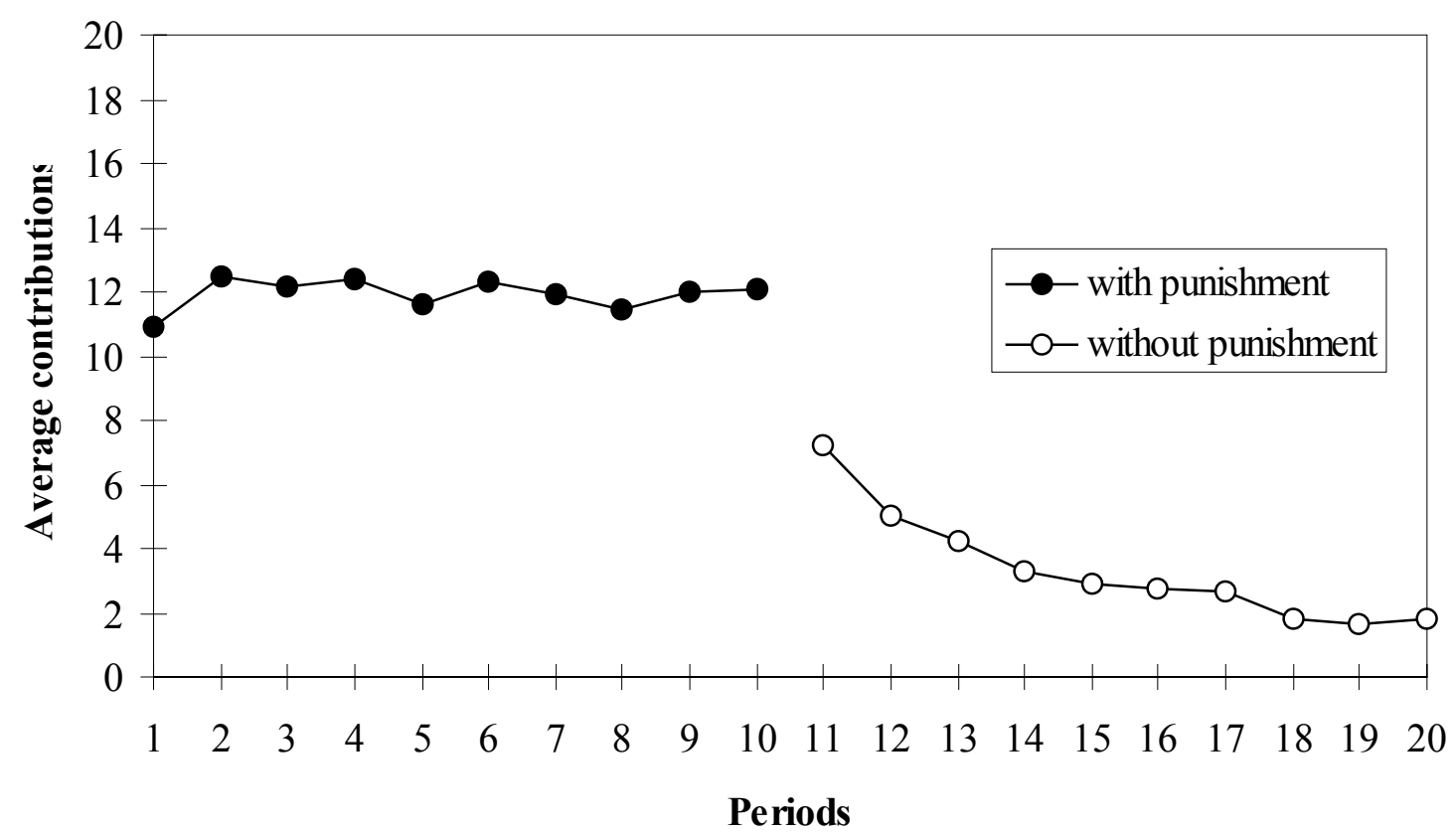

Figure 1b: Average contributions over time in the Stranger-treatment (Session 3)

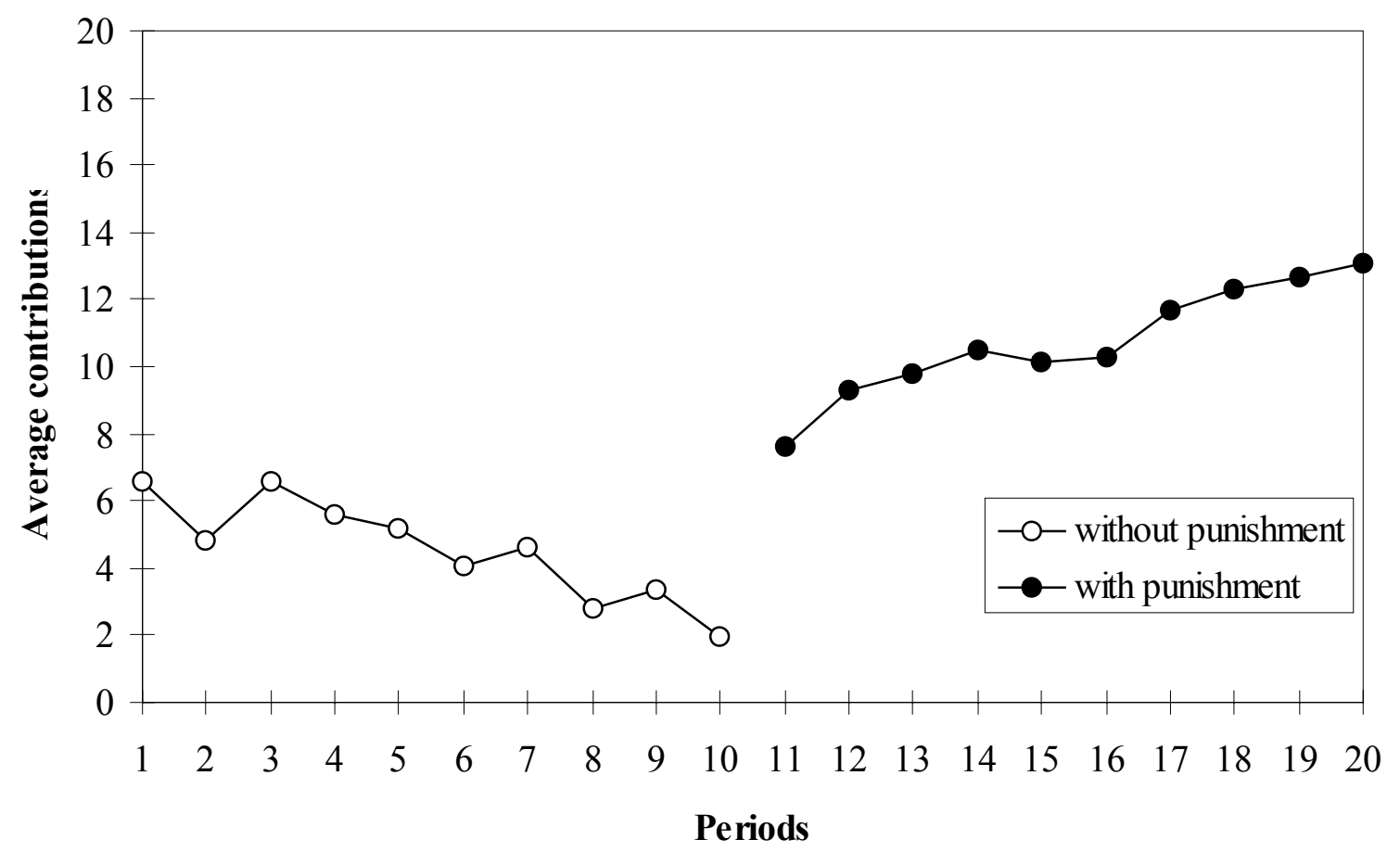


Figures $1 \mathrm{a}$ and $1 \mathrm{~b}$ depict the evolution of average contributions over time in both conditions. Figure 1a shows the results of Sessions 1 and 2 in which subjects had to play the punishment condition first. While the average contribution is stabilized around 12 tokens in the punishment condition there is immediately a significant drop in contributions in period $11 .{ }^{15}$ This decrease in the nopunishment condition continues until period 18 where the average contribution stabilizes slightly below 2 tokens. Figure $1 \mathrm{~b}$ shows the results of Session 3 in which subjects played the nopunishment condition first. In our view Figure $1 \mathrm{~b}$ reveals an even more remarkable fact. Whereas average contributions in the no-punishment condition converge again towards 2 tokens they immediately jump upward in period 11 and continue to rise until they reach 13 tokens in period ten. This indicates that the existence of punishment opportunities triggers the effectiveness of forces that completely remove the drawing power of the equilibrium with complete free-riding. In view of this evidence it is difficult to escape the conclusion that any model which predicts full free-riding is unambiguously rejected.

Results 1 and 2 deal only with average contributions. We are, however, also interested in the behavioral regularities at the individual level and how they are affected by the punishment opportunity. Result 3 summarizes the behavioral regularities in this regard.

RESULT 3: In the Stranger-treatment with punishment no stable behavioral regularity regarding individual contributions emerges while in the no-punishment condition full free riding emerges as the focal individual action.

A first indication for the absence of a behavioral standard in the punishment condition is provided in Table 3. The table shows that the standard deviation of individual contributions is quite large in each session. Moreover, the standard deviation in the final period is roughly the same as in all periods together. This indicates that the variability of contributions does not decrease over time. The decisive evidence for Result 3 comes, however, from Figure 2 which provides information about the relative frequency of individual choices in the final periods of both Stranger-treatments. In the nopunishment condition the overwhelming majority (75 percent) of subjects chose $g_{i}=0$ in the final period. Thus, full free riding clearly emerges as the behavioral regularity in this condition. ${ }^{16}$ In contrast, in the punishment condition individual choices are scattered over the whole strategy space in the final period. ${ }^{17}$ Although the relative frequency of 12, 15 and 20 tokens is higher than that of other contribution levels even the most frequent choice $\left(g_{i}=15\right)$ only reaches a frequency of 14

\footnotetext{
${ }^{15}$ The null hypothesis that average contributions are the same in period 10 and 11 can be rejected on the basis of a Wilcoxon signed ranks test $(\mathrm{p}=0.0012)$.

${ }^{16}$ This holds also true if we examine the relative frequency of individual choices over the previous 9 periods. 55 percent of all choices are at $g_{i}=0$. The next frequent choices are $g_{i}=10$ (6.9 percent) and $g_{i}=5$ (5.2 percent).

${ }^{17}$ In this regard the final period is fully representative of the previous nine periods.
} 
percent. Thus, as our discussion in Section III suggests, subjects in the punishment condition were not able to coordinate on a specific contribution level different from $g_{i}=0$.

Figure 2: Distribution of contributions in the final periods of the Stranger treatment with and without punishment

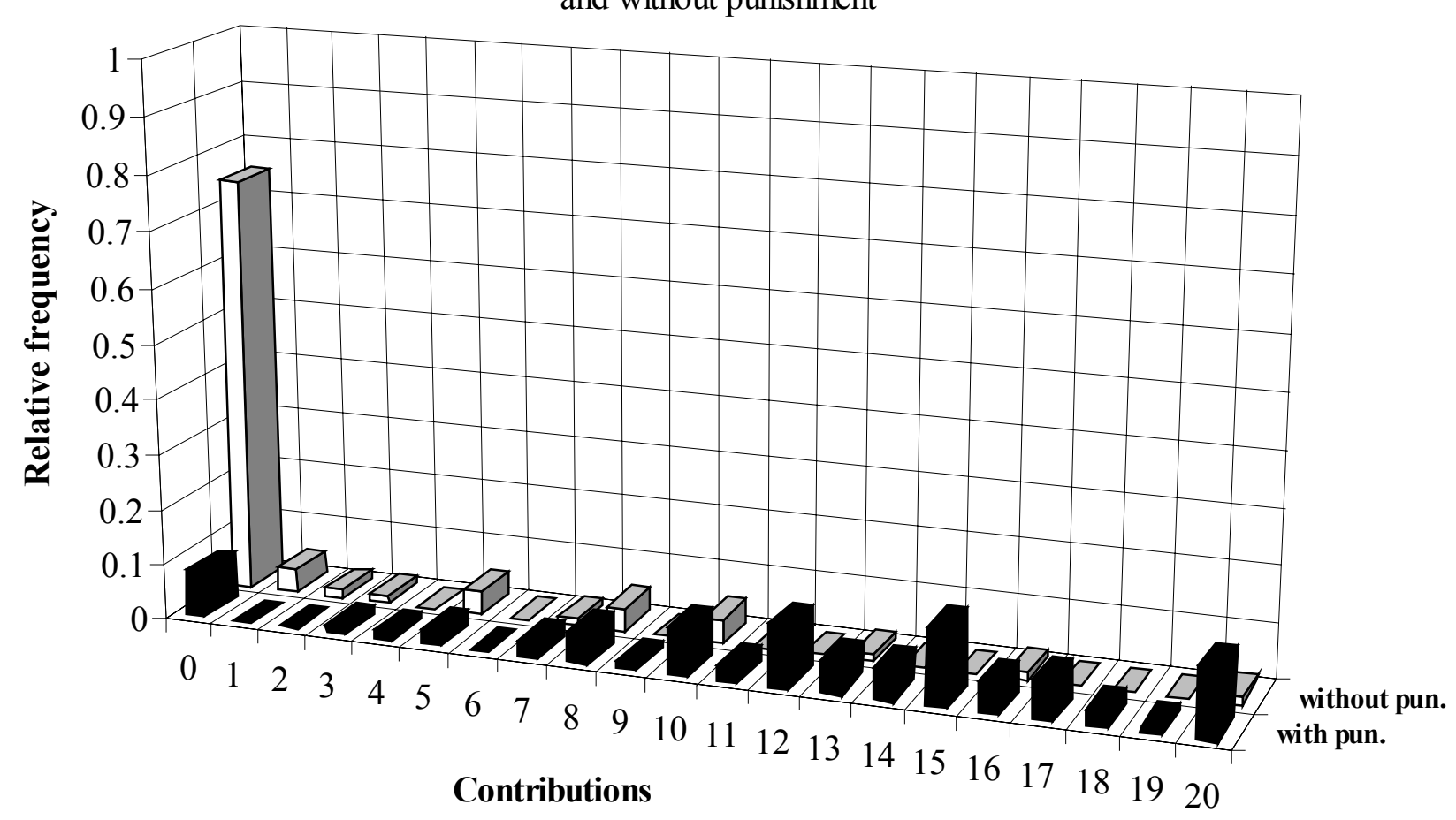

\section{B. The Impact of Punishment Opportunities in the Partner-Treatment}

As in the Stranger-treatments our first result in the Partner-treatments relates to average contributions over all periods:

RESULT 4: The existence of punishment opportunities also causes a large rise in the average contribution level in the Partner-treatment.

Table 4 provides the relevant support for Result 4. A comparison of column two and column three shows that all ten groups have substantially higher average contributions in the punishment condition. Therefore, the difference is highly significant $(\mathrm{p}=0.0026)$ according to a nonparametric Wilcoxon matched pairs test with group averages as observations. 
Table 4: Mean contributions in the Partner-treatments

\begin{tabular}{|c|c|c|c|c|}
\hline \multirow[b]{2}{*}{ groups } & \multicolumn{2}{|c|}{$\begin{array}{c}\text { mean contributions in } \\
\text { all periods }\end{array}$} & \multicolumn{2}{|c|}{$\begin{array}{c}\text { mean contributions in } \\
\text { the final periods }\end{array}$} \\
\hline & $\begin{array}{l}\text { without } \\
\text { punishment } \\
\text { opportunity }\end{array}$ & $\begin{array}{l}\text { with punishment } \\
\text { opportunity }\end{array}$ & $\begin{array}{l}\text { without } \\
\text { punishment } \\
\text { opportunity }\end{array}$ & $\begin{array}{l}\text { with punishment } \\
\text { opportunity }\end{array}$ \\
\hline 1 & $\begin{array}{c}7.0 \\
(6.3)\end{array}$ & $\begin{array}{l}17.5 \\
(4.3)\end{array}$ & $\begin{array}{c}5.8 \\
(5.1)\end{array}$ & $\begin{array}{l}19.5 \\
(1.0)\end{array}$ \\
\hline 2 & $\begin{array}{l}10.6 \\
(8.5)\end{array}$ & $\begin{array}{l}16.4 \\
(5.2)\end{array}$ & $\begin{array}{l}1.0 \\
(1.4)\end{array}$ & $\begin{array}{l}19.3 \\
(1.5)\end{array}$ \\
\hline 3 & $\begin{array}{c}6.7 \\
(7.8)\end{array}$ & $\begin{array}{l}18.4 \\
(3.6)\end{array}$ & $\begin{array}{c}6.3 \\
(9.5)\end{array}$ & $\begin{array}{l}20.0 \\
(0.0)\end{array}$ \\
\hline 4 & $\begin{array}{c}5.1 \\
(6.3)\end{array}$ & $\begin{array}{l}12.1 \\
(7.1)\end{array}$ & $\begin{array}{l}1.3 \\
(2.5)\end{array}$ & $\begin{array}{l}13.5 \\
(8.5)\end{array}$ \\
\hline 5 & $\begin{array}{c}6.4 \\
(7.2)\end{array}$ & $\begin{array}{l}14.3 \\
(7.0)\end{array}$ & $\begin{array}{l}1.8 \\
(2.9)\end{array}$ & $\begin{array}{c}10.5 \\
(11.0)\end{array}$ \\
\hline 6 & $\begin{array}{c}7.9 \\
(5.7)\end{array}$ & $\begin{array}{l}19.0 \\
(2.8)\end{array}$ & $\begin{array}{c}3.5 \\
(5.7)\end{array}$ & $\begin{array}{l}20.0 \\
(0.0)\end{array}$ \\
\hline 7 & $\begin{array}{c}7.4 \\
(7.1)\end{array}$ & $\begin{array}{l}19.0 \\
(3.4)\end{array}$ & $\begin{array}{l}2.5 \\
(2.9)\end{array}$ & $\begin{array}{l}20.0 \\
(0.0)\end{array}$ \\
\hline 8 & $\begin{array}{l}10.0 \\
(6.6)\end{array}$ & $\begin{array}{l}17.2 \\
(4.3)\end{array}$ & $\begin{array}{c}5.0 \\
(6.0)\end{array}$ & $\begin{array}{l}20.0 \\
(0.0)\end{array}$ \\
\hline 9 & $\begin{array}{c}3.9 \\
(5.9)\end{array}$ & $\begin{array}{l}17.0 \\
(5.0)\end{array}$ & $\begin{array}{c}0.0 \\
(0.0)\end{array}$ & $\begin{array}{l}20.0 \\
(0.0)\end{array}$ \\
\hline 10 & $\begin{array}{l}10.0 \\
(6.6) \\
\end{array}$ & $\begin{array}{l}19.0 \\
(2.1) \\
\end{array}$ & $\begin{array}{r}5.0 \\
(8.0) \\
\end{array}$ & $\begin{array}{l}19.5 \\
(1.0) \\
\end{array}$ \\
\hline mean & $\begin{array}{c}7.5 \\
(6.8) \\
\end{array}$ & $\begin{array}{l}17.0 \\
(4.5)\end{array}$ & $\begin{array}{c}3.2 \\
(4.4)\end{array}$ & $\begin{array}{l}18.2 \\
(2.3)\end{array}$ \\
\hline
\end{tabular}

Note: Numbers in parentheses are standard deviations. Groups 1-4 (Session 4) first played the punishment condition and then the no-punishment condition. Groups 5-10 (Session 5) played in the reverse order.

On average, subjects contribute between 1.5 times (group 2) and 4.3 times (group 9) more in the punishment condition. Thus, punishment opportunities are again highly effective in raising average contributions.

With regard to the evolution of average contributions over time the data support the following result.

RESULT 5: In the no-punishment condition of the Partner-treatment average contributions converge towards full free riding whereas in the punishment condition they increase and converge towards full cooperation. 
Again Table 4 provides a first indication. It shows that in the no-punishment condition the average contribution is only slightly above 3 tokens in the final period. In sharp contrast, the average contribution is above 18 tokens in the punishment condition. In five of the ten groups all subjects chose the maximum cooperation of 20 in the final period of the punishment condition. Further three groups exhibit average contributions of 19.3 or 19.5 tokens, respectively. A particularly remarkable fact represents the final period experience of group 9. Whereas all subjects chose full defection ( $g_{i}$ $=0)$ in the no-punishment condition all subjects chose full cooperation $\left(g_{i}=20\right)$ in the punishment condition.

Figures $3 \mathrm{a}$ and $3 \mathrm{~b}$ show the evolution of average contributions over time. Irrespective of whether subjects play the punishment condition at the beginning or after the no-punishment condition, their average contributions in the final period are considerably higher than in the first period of the punishment condition. The opposite is true in the no-punishment treatment. Moreover, at the switch points between the treatments there is a large gap in contributions in favor of the punishment condition. This indicates that the removal or the introduction of punishment opportunities immediately affects contribution behavior. ${ }^{18}$ Thus, Table 4 and Figures $3 \mathrm{a}$ and $3 \mathrm{~b}$ show that - in the Partner-treatment - punishment opportunities not only overturn the downward trend observed in dozens of no-punishment treatments; they also show that punishment opportunities render eight of ten groups capable of achieving almost full cooperation although according to the standard approach - full defection is the unique subgame perfect equilibrium.

A major purpose of the Partner-treatment with punishment is to enhance the possibilities for implicit coordination. We conjectured that this might enable subjects to converge towards a behavioral standard different from $g_{i}=0$. Result 6 shows that this is indeed the case.

\footnotetext{
${ }^{18}$ In Session 4 and in Session 5 average contributions in period 11 are significantly different from contributions in period 10 (Wilcoxon signed ranks tests, $\mathrm{p}=0.05$ (Session 4) and $\mathrm{p}=0.027$ (Session 5)). It is particularly remarkable that in Session 5 contributions in period 11 are even higher than in period 1 (Wilcoxon signed ranks test, p $=0.028$ ). All six groups of Session 5 contribute more in period 11 than in period 1.
} 
Figure 3a: Average contributions over time in the Partner-treatment (Session 4)

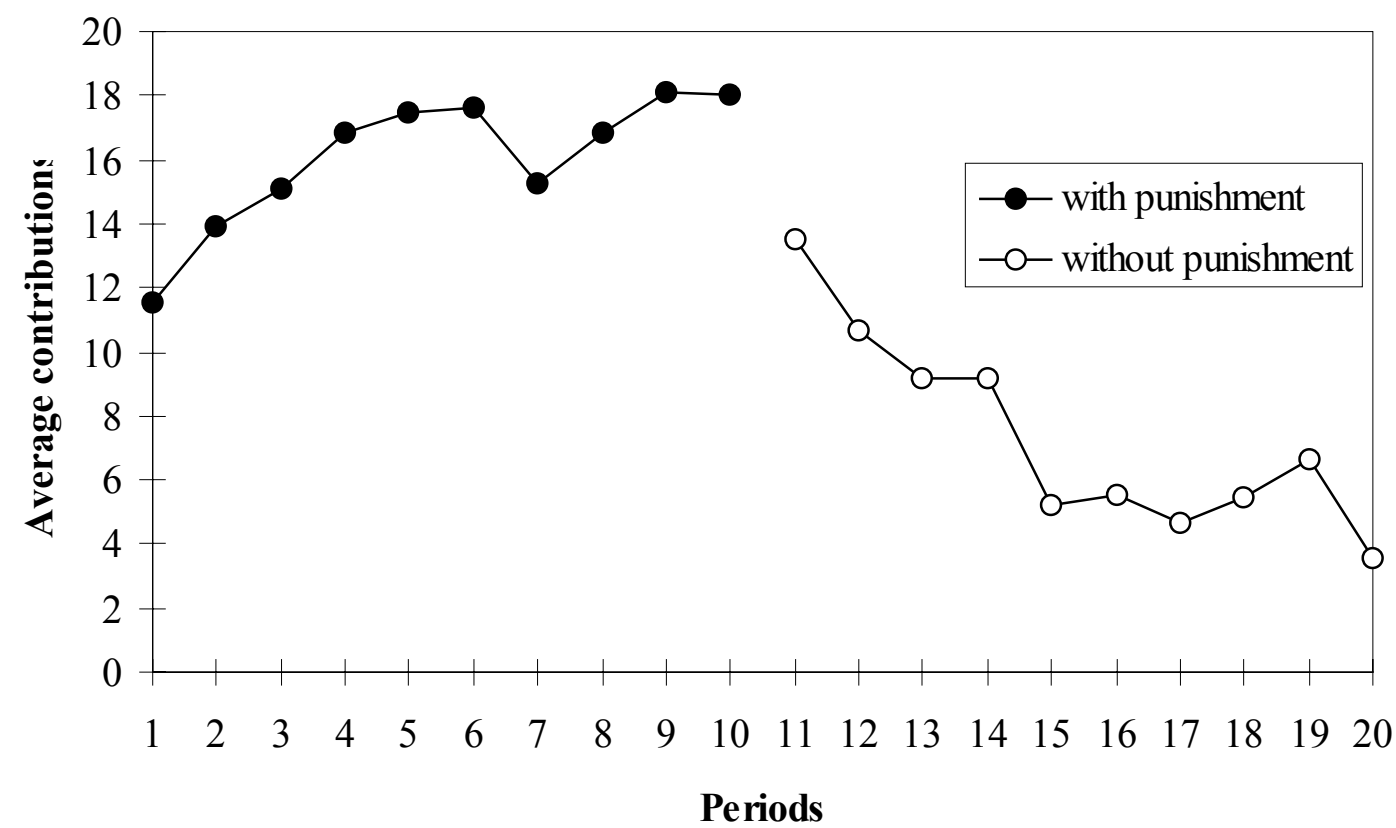

Figure 3b: Average contributions over time in the Partner-treatment (Session 5)

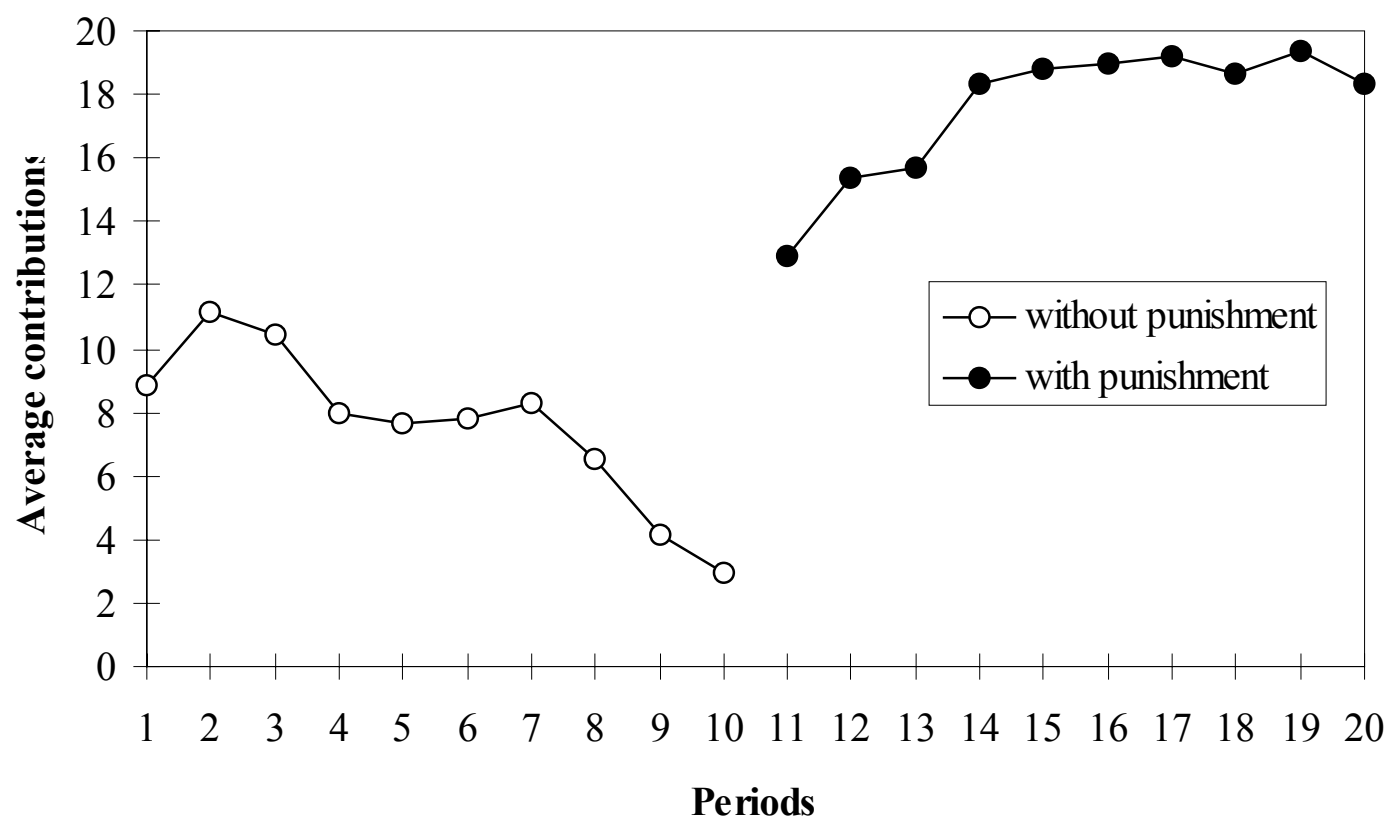


RESULT 6: In the Partner-treatment with punishment, full cooperation emerges as the dominant behavioral standard for individual contributions whereas in the absence of punishment opportunities full free riding is the focal action.

Evidence for Result 6 is given by Figure 4 which shows the relative frequency of individual contributions in the final periods of the Partner-treatments. In the punishment condition 82.5 percent of the subjects contribute the whole endowment whereas 53 percent of the same subjects free ride fully in the final period of the no-punishment condition. Moreover, in the no-punishment condition the majority of contributions is rather close to $g_{i}=0$. The message of Figure 4 seems so unambiguous that it requires little further comment.

Figure 4: Distribution of contributions in the final periods of the Partner-treatment with and without punishment

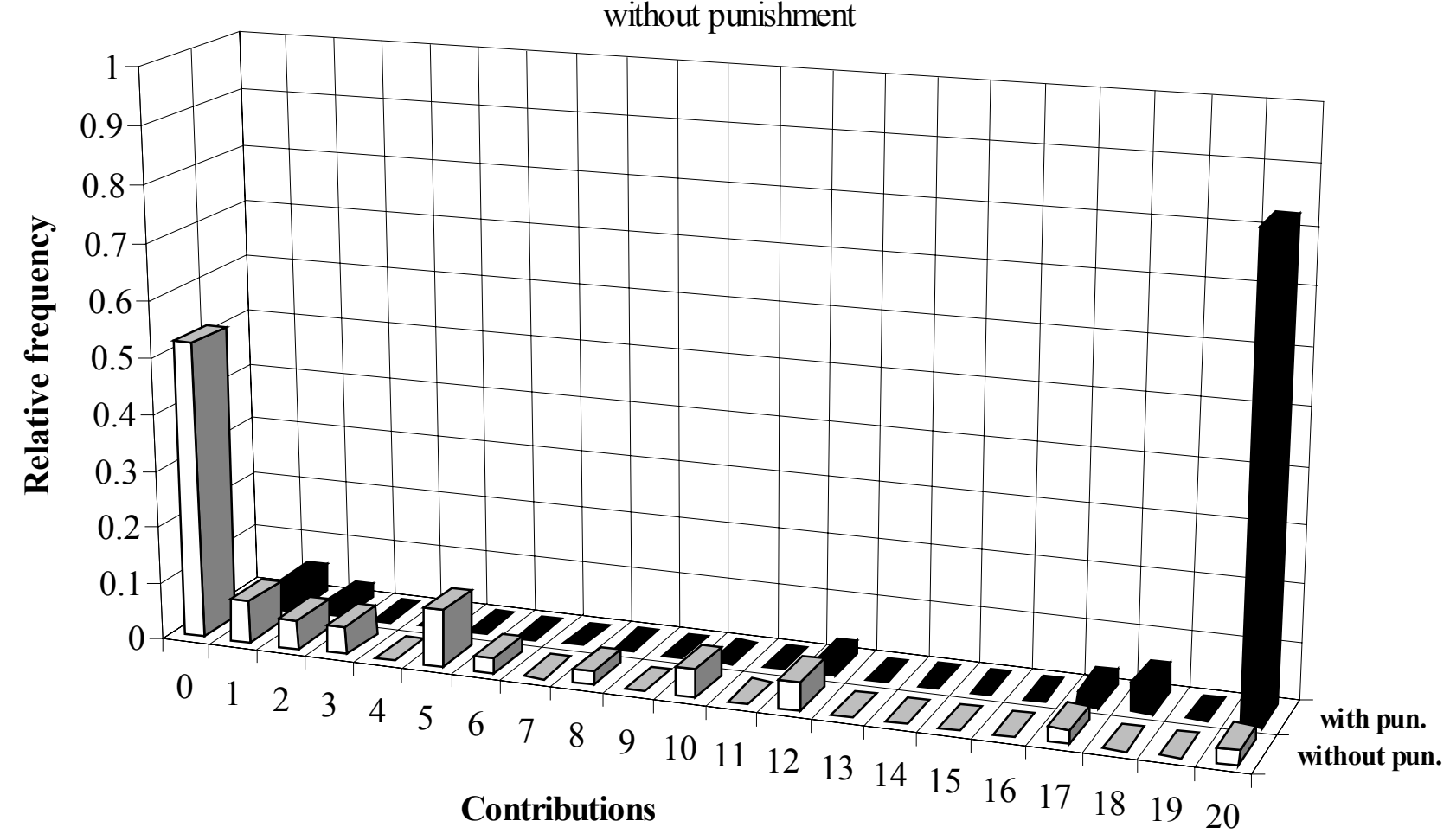




\section{Why Do Punishment Opportunities Raise Contributions?}

If there are indeed subjects who are willing to punish free riding and if their existence is anticipated by at least some potential free riders we should observe that punishment opportunities have an immediate impact on contributions. Figures 1 and 3 show that this is indeed the case. After the introduction of punishment opportunities in Session 3 (see Figure 1b) and Session 5 (see Figure 3b) there is an immediate increase in contributions. Moreover, after the removal of punishment opportunities in Sessions 1 and 2 (see Figure 1a) and Session 4 (see Figure 3a) contributions immediately drop to considerably lower levels. This suggests that potential free riders are indeed disciplined in the punishment condition. A more detailed look at the regularities of actual punishments provides further support for this view.

RESULT 7: In the Stranger and the Partner-treatment a subject is more heavily punished the more his contribution falls below the average contribution of other group members. Contributions above the average are punished much less and do not elicit a systematic punishment response.

Evidence for Result 7 is provided by Figure 5 and Table 5. In Figure 5 we have depicted the average punishment levels as a function of negative and positive deviations from the others' average contribution in the group. For example, a subject in the Partner-treatment, who contributed between 14 and 20 tokens less than the average, received on average 6.8 punishment points from the other group members. The numbers above the bars indicate the relative frequency of observations in the different deviation intervals.

Figure 5 shows that in both treatments negative deviations from the average are strongly punished. Moreover, in the domain of negative deviations, i.e., in the three intervals below -2 , the relation between punishment and deviations is clearly negatively sloped. The figure also indicates that there is a large drop in punishments if an individual's contribution is close to the average, i.e., in the interval $[-2,+2] .{ }^{19}$ Finally, the figure suggests that positive deviations are much less punished and that the size of the positive deviation has only a weak impact on the punishment activities by other group members. ${ }^{20}$

\footnotetext{
19 Figure 5 also provides further support for the emergence of a common behavioral standard for individual contributions in the Partner- but not in the Stranger-treatment. Note that 57 percent of all the individual contributions in the Partner-treatment are in the interval $[-2,+2]$ while only 26 percent are in this interval in the Stranger-treatment.

${ }^{20}$ One might ask why individuals with positive deviations get punished at all. According to a post-experimental questionnaire there are five potential reasons for this. (i) Random error. Since individuals can only err on one side at the punishment stage (i.e., rewarding others was not possible) each error shows up as a positive punishment. (ii) Subjects with very high individual contributions may view others' contributions as too low even if they are above the average. (iii) Subjects may want to earn more than others, i.e., they punish, even if others cooperate, to achieve a relative
} 
Figure 5: Received punishment points for deviations from others' average contribution

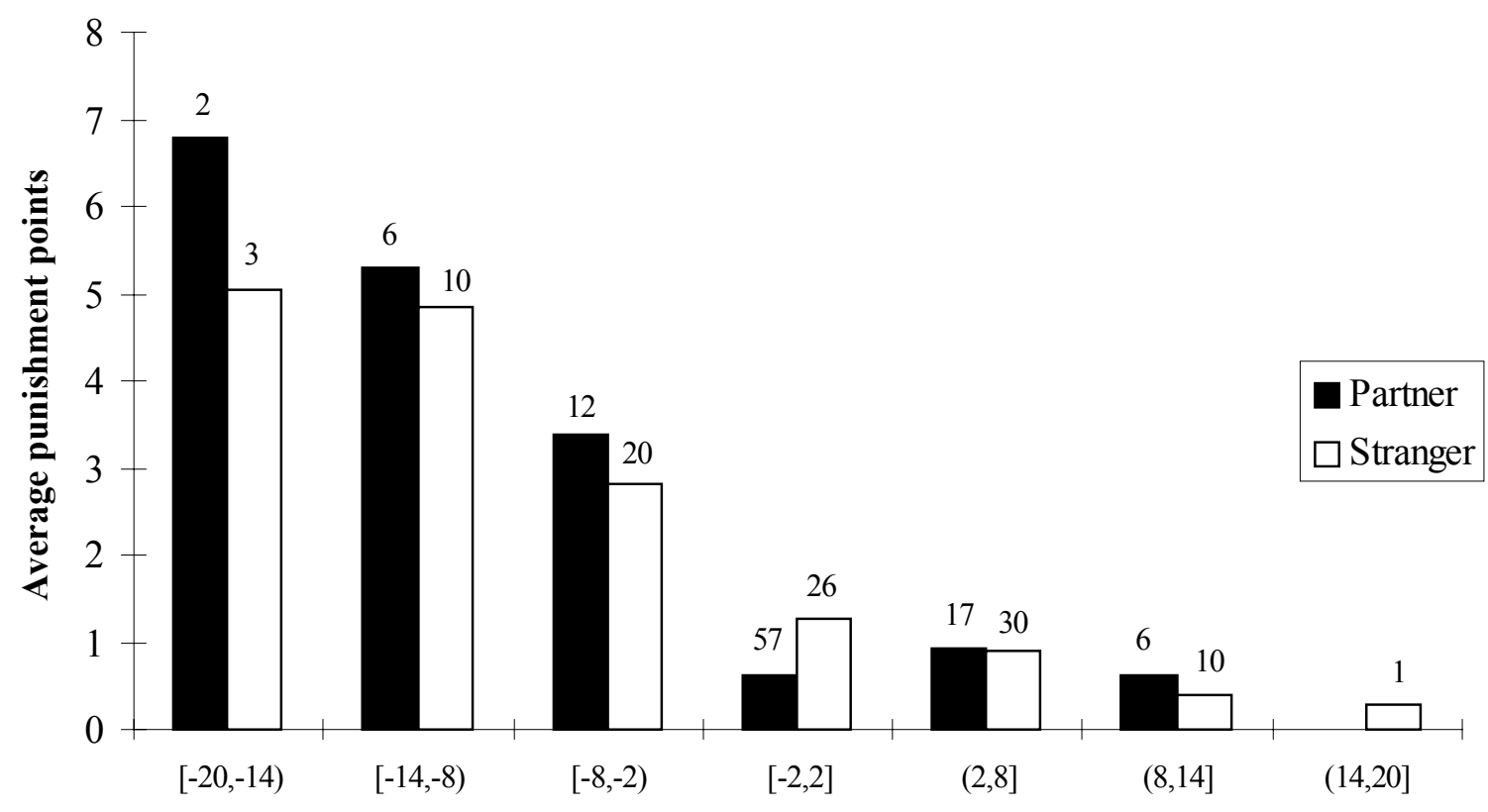

Deviation from the average contribution of the other group members

To provide formal statistical evidence for Result 7 we also conducted a regression analysis of punishment behavior. Table 5 contains the model and the OLS-regressions separately for the Stranger-treatment and the Partner-treatment. We also conducted Tobit regressions with the same variables. Yet, since they are almost identical with the OLS estimates we do not report them explicitly. The dependent variable is "received punishment points" of a subject and the independent variables comprise "others' average contribution" and the variables "positive deviation" and "absolute negative deviation", respectively. Figure 5 suggests that positive and negative deviations from the others' average contribution elicit different punishment responses. These variables are, therefore, included as separate regressors. The variable "absolute negative deviation" is the absolute value of the actual negative deviation of a subject's contribution from the others' average in case that his own contribution is below the average. This variable is zero if his own contribution is equal to or above the others' average. The variable "positive deviation" is constructed analogously. To model time effects, we included period dummies in the regression. The model also includes session

advantage. (iv) Spiteful revenge. Free riding subjects punish the cooperators because they expect to get punished by them. (v) Blind revenge. Subjects who get punished in $t-1$ may assume that punishment was mainly exerted by the cooperators. By punishing cooperators in $t$ they may take revenge. Note that by doing this they may punish the wrong target because our design rules out the possibility of identifying individual contribution histories. 
dummies in the Stranger-treatment and group dummies in the Partner-treatment to control for fixed effects (see Königstein (1997)).

The results in Table 5 support the evidence from Figure 5. In both treatments the coefficient of the "absolute negative deviation" is positive and highly significant. Thus, the more an individual's contribution falls short of the average the more she gets punished. In contrast, the size of the positive deviation has no significant impact on the size of the punishment. It is interesting that in the Partner-treatment it is only the negative deviation that affects punishment levels systematically while the level of the others' average contribution has no significant impact. The low value and the insignificance of the coefficient on "others' average contribution" suggests that only deviations from the average were punished. This may be taken as evidence that in the Partnertreatment subjects quickly established a common group standard that did not change over time. If, instead, there would have been subjects who wanted to raise, say, the group standard one should observe that a given negative deviation from the average is punished less the higher that average is. This is exactly what we observe in the Stranger-treatment where the coefficient on "others' average contribution" is negative. The fact that there were subjects in the Stranger-treatment who wanted to raise the group standard is consistent with previous evidence which shows that subjects in the Stranger-treatment could not establish a common behavioral standard.

Table 5 - The determinants of getting punished: Regression results

\begin{tabular}{c|cc}
\hline \hline \multirow{2}{*}{$\begin{array}{c}\text { independent } \\
\text { variables }\end{array}$} & $\begin{array}{c}\text { dependent variable: } \\
\text { received punishment points }\end{array}$ \\
\cline { 2 - 3 } constant & $\begin{array}{c}2.7363^{* * *} \\
(0.0485)\end{array}$ & $\begin{array}{c}\text { Stranger-treatment } \\
\text { Partner-treatment }\end{array}$ \\
\hline others' average & $-0.0735^{* * *}$ & $(0.6797)$ \\
contribution & $(0.0239)$ & -0.0108 \\
abs. neg. deviation & $0.2428^{* * *}$ & $(0.0457)$ \\
& $(0.0325)$ & $0.4168 * * *$ \\
positive deviation & -0.0147 & $(0.0510)$ \\
& $(0.0264)$ & -0.0357 \\
& & $(0.0355)$ \\
& $\mathrm{N}=720$ & $\mathrm{~N}=440$ \\
& $\mathrm{~F}[14,705]=39.0 * * *$ & $\mathrm{~F}[21,378]=41.3 * * *$ \\
& $\mathrm{adj} . \mathrm{R}^{2}=0.43$ & $\mathrm{adj} . \mathrm{R}^{2}=0.68$ \\
& $\mathrm{DW}=1.96$ & $\mathrm{DW}=1.89$ \\
\hline \hline
\end{tabular}

Note: Standard errors in parentheses. * denotes significance at the 10-percent level, ** at the 5-percent level and *** at the 1-percent level. To control for time and matching groups, the regression model also contains period dummies and dummies for matching groups (i.e., session dummies in the Stranger-treatment and dummies for each independent group in the Partner-treatment). Results are corrected for heteroskedasticity. Tobit estimations yield similar results. 
The pattern of punishment indicated by Figure 5 and Table 5 shows that free riders can escape or at least reduce the received punishment substantially by increasing their contributions relative to the other group members. The response of subjects who actually were punished suggests that they understood this. In the Partner-treatment we observed 125 sanctions against subjects who contributed less than their endowment. In 89 percent of these cases the punished subject increased $g_{i}$ immediately in the next period with an average increase of 4.6 tokens. In the Stranger-treatment we have 368 such cases. In 78 percent of these cases $g_{i}$ increased in the next period by an average of 3.8 tokens. These numbers suggest that actual sanctions were rather effective in immediately changing the behavior of the sanctioned subjects. Subjects seemed to have had a clear understanding of why they were punished and how they should respond to the punishment.

\section{Payoff Consequences of Punishment}

A major effect of the punishment opportunity is that it reduces the payoff of those with a relatively high propensity to free ride. In the following we call those subjects "free riders" who chose $g_{i}=0$ in more than 5 periods of the no-punishment treatment. 20 percent of subjects in the Partner- and 53 percent in the Stranger-treatment obey this definition of a free rider. In the Stranger-treatment with punishment opportunities the overall payoff of the free riders is reduced by 24 percent relative to the no-punishment condition; in the Partner-treatment the payoff reduction is 16 percent. This payoff reduction is driven by two sources. First, free riders are punished more heavily and second, they contribute more to the project in the punishment condition. On average, free riders raise their contributions between 10 and 12 tokens, i.e., by 50 to 60 percent of their endowment, relative to the no-punishment condition. However, there is also a force that works against the payoff reduction for free riders because the other subjects (the "non-free riders") also contribute more in the punishment condition. This limits the payoff reduction for the free riders.

What are the aggregate payoff consequences of the punishment condition? To examine this question we compute the difference in the average group payoff between the punishment and the no-punishment condition and normalize this difference by the average group payoff of the nopunishment condition. This gives us the relative payoff gain of the punishment condition. Result 8 summarizes the evolution of the relative payoff gain for the Partner- and the Stranger-treatment.

RESULT 8: In both the Stranger and the Partner-treatment the punishment opportunity initially causes a relative payoff loss. Yet, towards the end there is a relative payoff gain in both treatments. 
Support for Result 8 is provided by Figure 6 which shows that in both treatments the relative payoff loss is roughly 40 percent in period 1 . Yet, while there is already a relative payoff gain in period 4 of the Partner treatment it takes 9 periods in the Stranger-treatment to also achieve a relative payoff gain. In the final period the relative payoff gain is roughly 20 percent in the Partner- and 10 percent in the Stranger-treatment. The payoff differences in the Partner-treatment are statistically significant. According to a Wilcoxon matched pairs test the null hypothesis that groups' average income in periods 8-10 is identical across conditions can be rejected in favor of the alternative hypothesis that group incomes are higher in the punishment condition $(p<0.029) .^{21}$

Figure 6: Average payoff gain of the punishment relative to the no-punishment condition

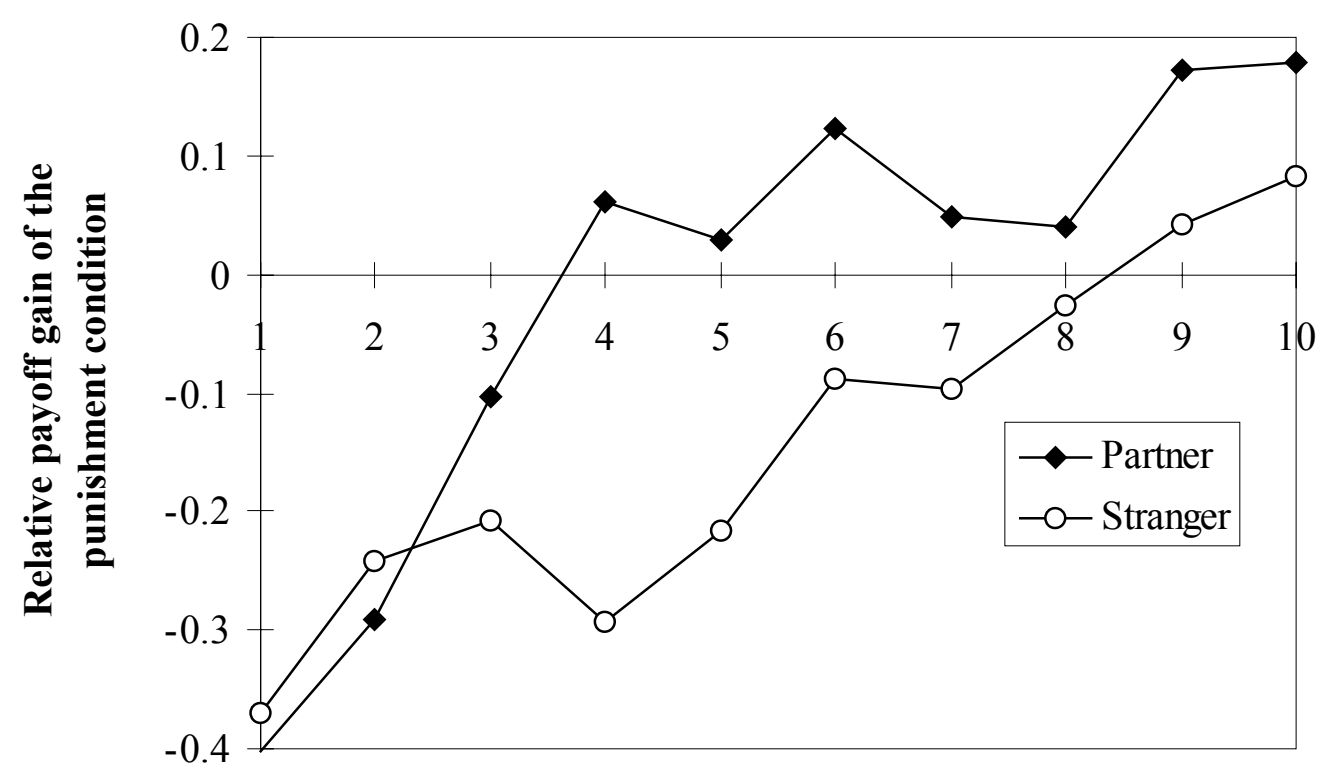

Period

The temporal pattern of relative payoff gains exhibited by Figure 6 is due to three sources: (i) In the Partner treatment, in particular, contributions are lower in the early periods of the punishment condition than during the later periods. (ii) This caused much more punishment activities in the early periods. (iii) Contributions gradually decline over time in the no-punishment condition. Taken together, Result 8 suggests that the presence of punishment opportunities eventually leads to

\footnotetext{
${ }^{21}$ Results are qualitatively the same if we take group incomes in period 9-10 or only in period 10.
} 
pecuniary efficiency gains. To achieve these gains it is, however, necessary to establish the full credibility of the punishment threat by actual punishments.

\section{E. Partners, Strangers and Perfect Strangers}

The random group composition in each period of the Stranger treatment ensures that the probability of meeting the same group members in future periods is very low, yet not zero. As a consequence, the behavior of some subjects might have been affected by the expectation of meeting the same subjects in future periods again. For example, some subjects might have been willing to punish because they expected some, although very diluted, private benefit in terms of higher future cooperation by the punished free riders. This motive could, of course, play no role in period ten. However, for periods 1-9 it cannot be completely ruled out.

To see whether the small probability of meeting the same people again is behaviorally important we conducted two Perfect Stranger-sessions. In each of the two sessions there were $N=$ 24 subjects who played first in the punishment condition for six periods and afterwards in the nopunishment condition for six periods. ${ }^{22}$ In each session we ensured that every subject in a given condition met every other subject exactly once in this condition, i.e., the probability of being rematched was zero. Subjects were explicitly informed that they will never meet any other subject twice.

In Figure 7 we compare the average contribution in the Stranger- and the Perfect Strangertreatment. Although average contributions seem to be slightly lower in the Perfect Stranger treatment the null hypothesis of equal contribution levels cannot be rejected on the basis of MannWhitney tests. In the punishment condition the null hypothesis cannot be rejected whether we take individual contributions in period one $(p>0.30)$, or individual average contributions over all periods $(p>0.29)$, or individual contributions in the final period $(p>0.77)^{23}$. Likewise, in the nopunishment condition the null hypothesis cannot be rejected irrespective of which data we take $(p>$ 0.59 in period one, $p>0.38$ in case of individual averages over all periods, $p>0.63$ in the final period).

Figure 7 shows that the big behavioral differences between the punishment and the nopunishment condition also emerge in the Perfect Stranger-treatment. This is no surprise in view of the punishment regularities, which are also very similar to the pattern in the Stranger-treatment. In

\footnotetext{
${ }^{22}$ As before (see footnote 9), subjects did not know that after the first treatment (six periods) there will be a further treatment. Note also that with $\mathrm{N}=24$ and $n=4$ six periods is the maximum number of periods compatible with a zero rematching probability.

${ }^{23}$ The final period is given by period ten in the Stranger- and by period six in the Perfect Stranger-treatment.
} 
the Perfect Stranger-treatment negative deviations from the average contribution of the other group members are as heavily punished as in the Stranger treatment while positive deviations have no systematic impact on received punishment points. Likewise, the vast majority of punishments is executed by the high contributors and punishment occurs even in the final period.

Figure 7: Average contributions over time in the Partner-, Stranger-, and PerfectStranger treatment when the punishment condition is played first

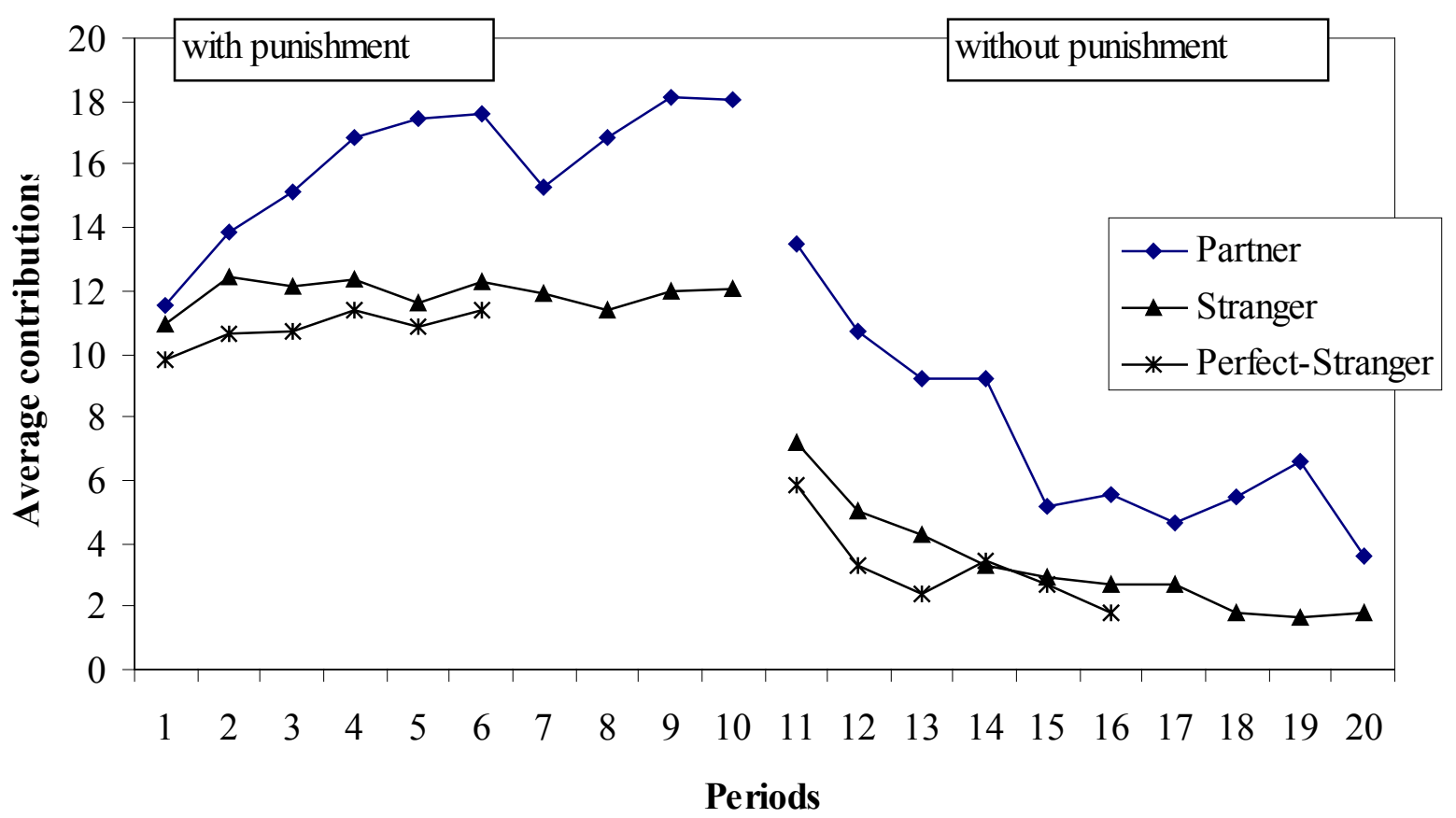

In our view the fact that the behavior in the Stranger- and the Perfect Stranger-treatment is very similar indicates that our Stranger treatment represents a good approximation to true one-shot experiments. The small probability of being rematched with the same people seems to have no significant behavioral impact. As Figure 7 reveals the really big differences occur between the Partner-treatment and the Stranger-treatment. This is interesting insofar as, starting with Andreoni (1988), there has been an intensive discussion in the literature whether contributions are higher in the Partner-treatment or not. With regard to this question our results suggest the following: "Partners" contribute significantly more than "Strangers" if we take subjects' average contribution over all periods as observations (Mann-Whitney Test, $p<0.001$ in both the punishment and the nopunishment condition). However, while in the punishment condition the difference between "Partners" and "Strangers" strongly increases over time and becomes largest in the final period ( $p<$ $0.0001)$, the behavioral differences decrease over time in the no-punishment condition. In period ten 
of the no-punishment condition the null hypothesis of no treatment differences cannot be rejected at the 5 percent level $(p=0.069$, Mann-Whitney Test).

From a game theoretic viewpoint the large behavioral difference between "Partners" and "Strangers" in period ten of the punishment condition constitutes a fascinating anomaly. In game theoretic terms, i.e., in terms of available strategies and payoffs, period ten of the Partner- and the Stranger-treatment are completely identical because the game ends afterwards. Yet, due to different experiences subjects behave very differently in the two treatments. This highlights the importance of experience and learning for subjects' actual behavior. ${ }^{24}$

\section{Interpretation - Negative Emotions and Punishment}

In Section III we hypothesized that the interaction between selfish, conditionally cooperative and punishing subjects is a decisive factor in shaping the final outcomes. In the no-punishment treatment conditional cooperators and punishing subjects have virtually no opportunities to affect the behavior of the selfish subjects. Therefore, they have an incentive to adjust their contributions to those of the free riders. In the punishment condition they can, however, force selfish subjects to adjust contributions towards those levels that they consider as appropriate. As we have seen in the previous section the punishment and the no-punishment conditions generate indeed a completely different contribution behavior. While the majority of subjects fully free rides in the final period of the no-punishment conditions (75 percent in the Stranger-, 53 percent in the Partner- condition), nobody fully free rides in the Partner-treatment with punishment and only 8 percent free ride fully in the corresponding Stranger-treatment. Thus, the behavioral evidence as summarized in Result 1 to Result 8 is certainly consistent with the hypothesized impact of conditionally cooperative and punishing types. Moreover, in our view it seems difficult to provide alternative explanations of the observed behavioral regularities.

Pure altruism or warm glow altruism, for example, is not capable of explaining the widespread punishment of free riders. ${ }^{25}$ After all, why should an altruistic person reduce the payoffs of other subjects? Mere confusion or subjects' inability to reason rationally also seems to be a poor alternative explanation. In view of the fact that free riding is punished heavily it was quite rational for potential free riders to adjust contributions to the average contribution of other players. Likewise, if conditional cooperators anticipate and experience higher contribution levels from the

\footnotetext{
${ }^{24}$ On the importance of experience for actual behavior see also Erev and Roth (1998) and Schotter and Sopher (1998).

${ }^{25}$ Pure altruism means that a subject's utility is increasing in the total group payoff. In case of warm glow preferences a subject derives a fixed amount of utility from the act of cooperation, irrespective of the payoff consequences of cooperation. For these definitions see Andreoni (1990). Note that we do not say that pure altruism or warm glow altruism is generally unimportant. For evidence in favor of warm glow altruism see Palfrey and Prisbrey (1997). We 'only' say that neglecting the drive to punish free riders means that one neglects a potentially very important force.
} 
other group members it is rational for them to also contribute more than in the no-punishment condition. The rational anticipation of punishment for below-average contributions and the importance of the second stage for the contribution behavior has also been confirmed by a postexperimental questionnaire. ${ }^{26}$

Belief-based or reinforcement learning models that rely on purely selfish preferences (Camerer and Ho 1998, Erev and Roth 1998) also have difficulties in explaining important features of the data. They cannot explain, e.g., why subjects' contributions jump downwards or upwards after the first treatment condition in an experimental session. The difficulty of explaining the jumps arises from the fact that these models do not take into account that there are many subjects who anticipate the presence of punishing types and the role they play in the punishment and the nopunishment condition. If the presence of punishing types is anticipated it is, however, quite rational for the selfish types to raise their contributions when they move into the punishment condition and to lower their contributions when they move into the no-punishment condition. ${ }^{27}$

In view of the punishment pattern subjects' contribution behavior seems quite rational. A big question is, however, why many subjects are willing to punish free riders in a one-shot context although this is costly. This question can be subdivided into two questions: (i) What is the proximate source of punishment? (ii) What is the ultimate, i.e., evolutionary reason for the existence of punishing subjects? It is not the purpose of the present paper to provide an answer to the second question. ${ }^{28}$ With regard to the first question we believe, however, that emotions play a key role.

In our view it seems quite likely that free riding causes strong negative emotions among the cooperators and that these emotions, in turn, trigger the willingness to punish free riders. This hypothesis has been advanced by Hirshleifer (1987) and Frank (1988). ${ }^{29}$ If it is correct we should observe particular emotional patterns in response to free riding. To elicit these patterns we confronted subjects with different contribution scenarios (see Table 6). ${ }^{30}$ After they read a scenario they had to indicate the intensity of negative feelings towards a target person on a seven point scale ( $1=$ 'not at all', ..., 7 = 'very much'). The difference between Scenario 1 and 1' is that the "non-free riders" contribute relatively much in Scenario 1 and relatively little in Scenario 1'. In Scenario 2 and 2' subjects themselves were hypothetically put into the position of a free rider. Then they had to

\footnotetext{
${ }^{26}$ The details of the questionnaire results are available on request.

${ }^{27}$ To do justice to learning models we should add that no static equilibrium model is capable of explaining the time path of contributions within a given treatment. Our argument above is not directed against learning models per se. It just indicates the limits of purely backward looking models that assume purely selfish preferences.

${ }^{28}$ There are a few papers that aim at providing evolutionary explanations of punishment traits in a free riding context (Axelrod 1986, Boyd and Richerson 1992, Bowles and Gintis 1998, Sethi and Somanathan 1996). Evolutionary explanations are also given in Güth (1995), Hirshleifer (1987) and Frank (1988).

${ }^{29}$ For an interesting survey about the role of emotions in economic theory see Elster (1998).

${ }^{30}$ As in the questionnaire that elicited the willingness to contribute conditionally subjects who participated in the emotions questionnaire did not participate in the experiments described in Sections II - IV. For the procedures see footnote 21 .
} 
indicate their expectation about the intensity of the other players' anger and annoyance. As before, the difference between Scenario 2 and 2' is that in Scenario 2 the other players contribute relatively much while in Scenario 2' they contribute relatively little.

Table 6: Emotions towards free riders - Scenarios

\begin{tabular}{|c|c|c|}
\hline Emotional response: & Scenarios: & Results: \\
\hline $\begin{array}{l}\text { own emotion towards a free } \\
\text { rider }\end{array}$ & $\begin{array}{l}\text { Scenario } 1 \text { and 1' } \\
\text { (numbers in brackets relate to Scenario 1') } \\
\text { "You decide to contribute 16 [5] francs to the } \\
\text { project. The second group member contributes } \\
14 \text { [3] and the third } 18 \text { [7] francs. Suppose the } \\
\text { fourth member contributes } 2 \text { francs to the } \\
\text { project. You now accidentally meet this } \\
\text { member. Please indicate your feeling towards } \\
\text { this person." }\end{array}$ & $\begin{array}{l}\text { Scenario 1: } \\
\text { mean: } 5.7 \\
\text { median: } 6 \\
\text { std.dev: } 2.3 \\
\text { Scenario 1': } \\
\text { mean: } 3.8 \\
\text { median: } 4 \\
\text { std.dev: } 2.0\end{array}$ \\
\hline $\begin{array}{l}\text { expected feeling of others } \\
\text { towards oneself if oneself } \\
\text { is a free rider }\end{array}$ & $\begin{array}{l}\text { Scenario } 2 \text { and 2' } \\
\text { (numbers in brackets relate to Scenario 2') } \\
\text { "Imagine that the other three group members } \\
\text { contribute 14, } 16 \text { and } 18 \text { [3, } 5 \text { and 7] francs to } \\
\text { the project. You contribute } 2 \text { francs to the } \\
\text { project and the others know this. You now } \\
\text { accidentally meet one of the other members. } \\
\text { Please indicate the feelings you expect from } \\
\text { this member towards you." }\end{array}$ & $\begin{array}{l}\text { Scenario 2: } \\
\text { mean: } 6.3 \\
\text { median: } 7 \\
\text { std.dev: } 2.3 \\
\text { Scenario 2': } \\
\text { mean: } 4.2 \\
\text { median: } 4 \\
\text { std.dev: } 2.1\end{array}$ \\
\hline
\end{tabular}

Note: Subjects had to indicate their feelings of anger and annoyance on a 7-point scale $(1=$ 'not at all' ... $7=$ 'very much'). Scenarios 1', and 2', resp., were exactly the same as scenarios 1 and 2, resp., except that they were based on the contribution levels indicated in square brackets. $\mathrm{N}=33$. None of these subjects participated in the experiment.

Several results emerge from Table 6. First, the table indicates that a free rider triggers very strong negative emotions in the other subjects if these subjects contribute relatively much (Scenario 1). The median intensity of negative feelings in this case is 6 on a 7-point scale. Second, the negative feelings a free rider anticipates from other subjects who contribute relatively much (Scenario 2) are even higher. The median intensity of anticipated negative emotions even coincides with the maximum intensity of negative emotions. Third, the (anticipated) intensity of negative emotions towards a free rider in case that others contribute relatively little (Scenario 1' and 2') is smaller but still considerable. Both the median intensity of the own negative emotion and the anticipated median intensity of others if oneself is the free rider are 4 on the 7-point scale. Note that this decrease in the intensity of negative emotions in Scenarios 1' and 2' relative to the case where 
others contribute relatively much (Scenarios 1 and 2) occurs although the free rider's contribution is kept constant. This shows that the intensity of negative feelings towards free riders varies with the size of the negative deviation from others' average contribution. The results of Table 6 show that free riding causes strong negative emotions and that such emotions are anticipated by most people. In addition, the emotional pattern is consistent with the hypothesis that emotions trigger punishment for the following reasons:

First, if negative emotions trigger punishment, one would expect that the majority of punishment activities is executed by those who contribute more against those who contribute less. This is the case both in the Stranger- and the Partner-treatment. Between 60 and 70 percent of all punishment activities follow this pattern. Second, remember that non-strategic punishment increases with the size of the negative deviation from the average. This is exactly what one would expect if negative emotions are the cause of the punishment because negative emotions are the more intense the more the free rider deviates from the others' average contribution. Third, if negative emotions cause punishment, the fact that most people are well aware that they trigger strong negative emotions (see Scenario 2 and 2') in case of free riding renders the punishment threat immediately credible. Therefore, we should detect an immediate impact of the punishment opportunity on contributions at the switch points between the punishment and the no-punishment condition. Remember that this is exactly what we observe. The introduction (elimination) of the punishment opportunity leads to an immediate rise (fall) in contributions (see Figures 1 and 3). Taken together, these regularities support the view that emotions are guarantors of credible threats.

\section{Concluding Remarks}

This paper provides evidence that spontaneous and uncoordinated punishment activities give rise to heavy punishment of free riders. In the Perfect Stranger- and the Stranger-treatment this punishment occurs although it is costly and provides no or virtually no future private benefits for the punishers. The more an individual negatively deviates from the contributions of the other group members the heavier is the punishment. Therefore, the punishment opportunity gives rise to credible threats against potential free riders and causes a large increase in contributions: Very high or even full cooperation can be achieved and maintained in the punishment condition whereas the same subjects converge towards full defection in the no-punishment condition. We do not know of many instances in which a variation in the behavioral environment that should - according to the standard economic approach - have no effect, causes such a large behavioral difference. We also provide evidence that 
free riding causes strong negative emotions among cooperating subjects. Moreover, the pattern of emotional responses to free riding is consistent with the hypothesis that negative emotions trigger the willingness to punish.

In our view emotion-based punishment of free riding also plays an important role in real life. It seems, for example, rather likely that many drivers feel an impulse to punish those who are butting into line, that - under team production - shirking workers elicit strong disapproval among their peers, and that strike breaking workers face the spontaneous hostility of their striking colleagues. The enormous impact of the punishment opportunities on contributions in our experiment suggests that a neglect of the widespread willingness to punish free riders faces the serious risk of making wrong predictions and, hence, giving wrong normative advice. Institutional and social structures that, theoretically, trigger the same behaviors in the absence of the willingness to punish may cause vastly different behaviors if the willingness to punish is taken into account. 


\section{References}

Andreoni, James (1988): "Why Free Ride? - Strategies and Learning in Public Goods Experiments", Journal of Public Economics 37, 291-304.

Andreoni, James (1990): "Impure Altruism and Donations to Public Goods: A Theory of Warm Glow Giving", Economic Journal C, 464-477.

Andreoni, James (1995): "Cooperation in Public-Goods Experiments: Kindness or Confusion?", American Economic Review 85, 891-904.

Axelrod, Robert (1986): "The Evolution of Norms", American Political Science Review, Vol. 80, 1095-1111.

Berg, Joyce and John Dickhaut, and Kevin McCabe (1995): "Trust Reciprocity and Social History", Games and Economic Behaviour, Vol. 10, 122-142.

Bowles, Samuel and Herbert Gintis (1998): "The Evolution of Strong Reciprocity", mimeo, University of Massachusetts at Amherst.

Boyd, Robert and Peter J. Richerson (1992): "Punishment Allows the Evolution of Cooperation (or Anything Else) in Sizable Groups", Ethology and Sociobiology, Vol. 13, 171-195.

Camerer, Colin and Richard Thaler (1995): "Ultimatum Games", Journal of Economic Perspectives 9, $209-220$.

Camerer, Colin and Teck Hua Ho (1998): "Experience Weighted Attraction Learning in Normal Form Games", forthcoming in Econometrica.

Coleman, James (1990): Foundations of Social Theory, The Belknap Press of Harvard University Press.

Croson, Rachel (1995): "Feedback in Voluntary Contributions Mechanisms: An Experiment in Team Production", Discussion Paper, Wharton School, University of Pennsylvania.

Croson, Rachel (1998): "Theories of Altruism and Reciprocity: Evidence from Linear Public Good Games", Discussion Paper, Wharton School, University of Pennsylvania.

Dawes, Robyn and Ríchard Thaler (1988): "Cooperation”, Journal of Economic Perspectives 2, 187 $-197$.

Elster, Jon (1998): “Emotions and Economic Theory”, Journal of Economic Literature 36, 47-74.

Erev, Ido and Alvin E. Roth (1998): "Predicting How People Play Games: Reinforcement Learning in Experimental Games With Unique, Mixed Strategy Equilibria", American Economic Review 88, 848-881.

Fehr, Ernst and Klaus Schmidt (1998): "A Theory of Fairness, Competition, and Cooperation", forthcoming in Quarterly Journal of Economics.

Fehr, Ernst Simon Gächter and Georg Kirchsteiger (1997): "Reciprocity as a Contract Enforcement Device - Experimental Evidence", Econometrica 65, 833-860.

Fehr, Ernst, and Armin Falk(1999): "Wage Rigidity in a Competitive Incomplete Contract Market", Journal of Political Economy 107, 106-134.

Fischbacher, Urs (1998): "z-Tree: Zurich Toolbox for Readymade Economic Experiments. Instruktionen für Experimentatoren", mimeo, University of Zurich.

Fischbacher, Urs, Simon Gächter and Ernst Fehr (1998): "Anomalous Behavior in Public Goods Experiments: The Role of Conditional Cooperation", Discussion Paper, University of Zurich. 
Francis, Hywel (1985): "The Law, Oral Tradition and the Mining Community", Journal of Law and Society 12, 267-271.

Frank, Robert (1988): Passions within Reason. The Strategic Role of the Emotions. New York: W.W. Norton \& Company.

Frank, Robert (1994): Microeconomics and Behavior. New York: W.W. Norton \& Company.

Güth, Werner (1995): "An Evolutionary Approach to Explaining Cooperative Behavior by Reciprocal Incentives", International Journal of Game Theory 24, 323-344.

Güth, Werner and Reinhard Tietz (1990): "Ultimatum Bargaining Behavior - A Survey and Comparison of Experimental Results", Journal of Economic Psychology 11, 417 - 449.

Heckathorn, Douglas (1996): “The Dynamics and Dilemmas of Collective Action”, American Sociological Review, 61.

Hirshleifer, David and Eric Rasmusen (1989): "Cooperation in a Repeated Prisoners' Dilemma with Ostracism", Journal of Economic Behavior and Organization 12, 87-106.

Hirshleifer, Jack (1987): "On the Emotions as Guarantors of Threats and Promises", in: John Dupré, The Latest on the Best. Essays on Evolution and Optimality, Cambridge, Mass.: MIT Press.

Königstein, Manfred (1997): "Measuring Treatment Effects in Experimental Cross-Sectional Time Series", mimeo, Humboldt-University at Berlin.

Ledyard, John (1995): "Public Goods: A Survey of Experimental Research", in: Handbook of Experimental Economics, ed. by John Kagel and Alvin Roth, Princeton University Press.

Ostrom, Elinor, James Walker and Roy Gardner (1992): "Covenants With and Without a Sword: Self-Governance is Possible", American Political Science Review 86, 404 - 417.

Palfrey, Thomas and Jeffrey Prisbrey (1997): "Anomalous Behavior in Public Goods Experiments: How Much and Why?" American Economic Review 87, 829-846.

Rabin, Matthew (1993): "Incorporating Fairness into Game Theory and Economics", American Economic Review 83, 1281-1302.

Roethlisberger, F. J. and W. J. Dickson, (1947): Management and the Worker: An Account of a Research Program Conducted by the Western Electric Company, Hawthorne Works, Chicago, Cambridge, MA: Harvard University Press.

Roth, Alvin (1995): "Bargaining Experiments", in: Handbook of Experimental Economics, ed. by John Kagel and Alvin Roth, Princeton University Press.

Schotter, Andrew and Barry Sopher (1998): "Coordination Conventions in Inter-Generational Games: An Experiment in Lamarckian Evolutionary Dynamics", Discussion Paper, New York University.

Sethi Rajiv and E. Somanathan (1996): "The Evolution of Social Norms in Common Property Resource Use", American Economic Review 86, 766-788.

Weimann, Joachim (1990): "Individual behavior in a free-riding experiment", Journal of Public Economics 54, 185 - 200.

Whyte, William (1955): Money and Motivation, New York: Harper and Brothers. 


\section{Appendix: Instructions}

The following instructions were originally written in german. We document the instructions we used in the stranger-treatment, were we first played the two-stage-game with punishment opportunities and second the one-stage, ordinary voluntary contributions game. The instructions in the other treatments were adapted accordingly. They are available upon request.

You are now taking part in an economic experiment which has been financed by various foundations for research promotion. If you read the following instructions carefully, you can, depending on your decisions, earn a considerable amount of money. It is therefore very important that you read these intructions with care.

The instructions which we have distributed to you, are solely for your private information. It is prohibited to communicate with the other participants during the experiment. Should you have any questions please ask us. If you violate this rule, we shall have to excluded you from the experiment and from all payments.

During the experiment we shall not speak of Francs but rather of Guilders. During the experiment your entire earnings will be calculated in Guilders. At the end of the experiment the total amount of guilders you have earned will be converted to Francs at the following rate:

$$
1 \text { Guilder }=5 \text { Rappen }
$$

Each participant receives a lump sum payment of $\mathbf{2 5}$ Guilders at the beginning of the experiment (as well as the 15 Francs for participating). This one-off payment can be used to pay for eventuell losses during the experiment. However, you can always evade losses with certainty through your own decisions. At the end of the experiment your entire earnings from the experiment plus the lump sum payment and the 15 Francs will be immediatley paid to you in cash.

The experiment is divided into different periods. In all, the experiment consists of 10 periods. In each period the participants are divided into groups of four. You will therefore be in a group with 3 other participants. The composition of the groups will change by random after each period. In each period your group will therefore consist of different participants.

In each period the experiment consists of two stages. At the first stage you have to decide how many points you would like to contribute to a project. At the second stage you are informed on the contributions of the three other group members to the project. You can then decide whether or how much to reduce their earnings from the first stage by distributing points to them.

The following pages describe the course of the experiment in detail:

\section{Detailed Information on the Experiment}

\section{The first Stage}

At the beginning of each period each participant receives 20 tokens. In the following we call this his or her endowment. Your task is to decide how to use your endowment. You have to decide how many of the 20 tokens you want to contribute to a project and how many of them to keep for yourself. The consequences of your decision are explained in detail below.

At the beginning of each period the following input-screen for the first stage will appear:

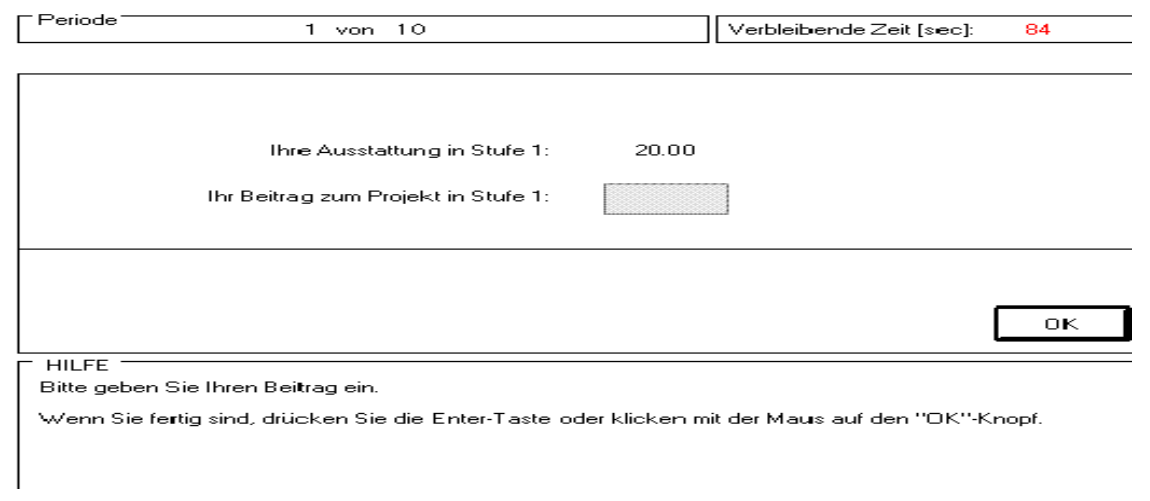

The number of the period appears in the top left corner of the screen. In the top right corner you can see how many more seconds remain for you to decide on the distribution of your points. Your decision must be made before the time displayed is 0 seconds. 
Your endowment in each period is 20 tokens. You have to decide how many points you want to contribute to the project by typing a number between 0 and 20 in the input field. This field can be reached by clicking it with the mouse. As soon as you have decided how many points to contribute to the project, you have also decided how many points you keep for your self: This is (20 - your contribution) tokens. After entering your contribution you must press the O.K. button (either with the mouse, or by pressing the Enter - key). Once you have done this your decision can no longer be revised.

After all members of your group have made their decision the following income screen will show you the total amount of points contributed by all four group members to the project (including your contribution). Also this screen shows you how many Guilders you have earned at the first stage.

The Income Screen after the first stage:

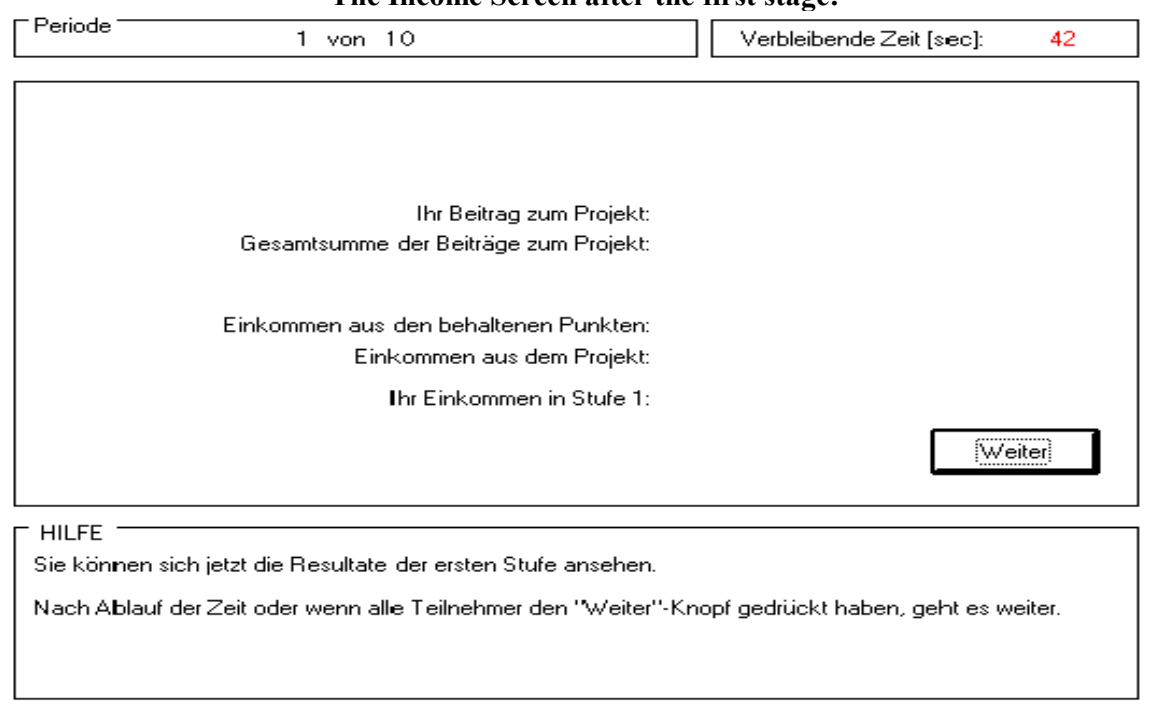

Your income consists of two parts:

1) the tokens which you have kept for yourself ("Income from tokens kept") whereby;

1 token $=1$ Guilder.

2) the "income from the project". This income is calculated as follows:

Your income from the project $=0.4 \mathrm{x}$ the total contribution of all 4 group members to the project.

Your income in Guilders at the first stage of a period is therefore:

(20 - your conribution to the project) $+0.4 *$ (total contributions to the project)

The income of each group member from the project is calculated in the same way, this means that each group member receives the same income from the project. Suppose the sum of the contributions of all group members is 60 points. In this case each member of the group receives an income from the project of: $0.4 * 60=24$ Guilders. If the total contribution to the project is 9 points, then each member of the group receives an income of $0.4 * 9=3.6$ Guilders from the project.

For each point, which you keep for yourself you earn an income of 1 Guilder. Supposing you contributed this point to the project instead, then the total contribution to the project would rise by one point. Your income from the project would rise by $0.4 * 1=0.4$ points. However the income of the other group members would also rise by 0.4 points each, so that the total income of the group from the project would rise by 1.6 points. Your contribution to the project therefore also raises the income of the other group members. On the other hand you earn an income for each point contributed by the other members to the project. For each point contributed by any member you earn $0.4 * 1=0.4$ points.

In the first two periods you have 45 seconds and in the remaining periods 30 seconds to view the income screen. If you are finished with it before the time is up, please press the continue button (again by using the mouse or pressing the Enter key). The first stage is then over and the second stage commences.

\section{The second Stage}


At the second stage you now see how much each of the other group members contributed to the project. At this stage you can also reduce or leave equal the income of each group member by distributing points. The other group members can also reduce your income if they wish to. This is apparent from the input screen at the second stage:

The input screen at the 2nd stage

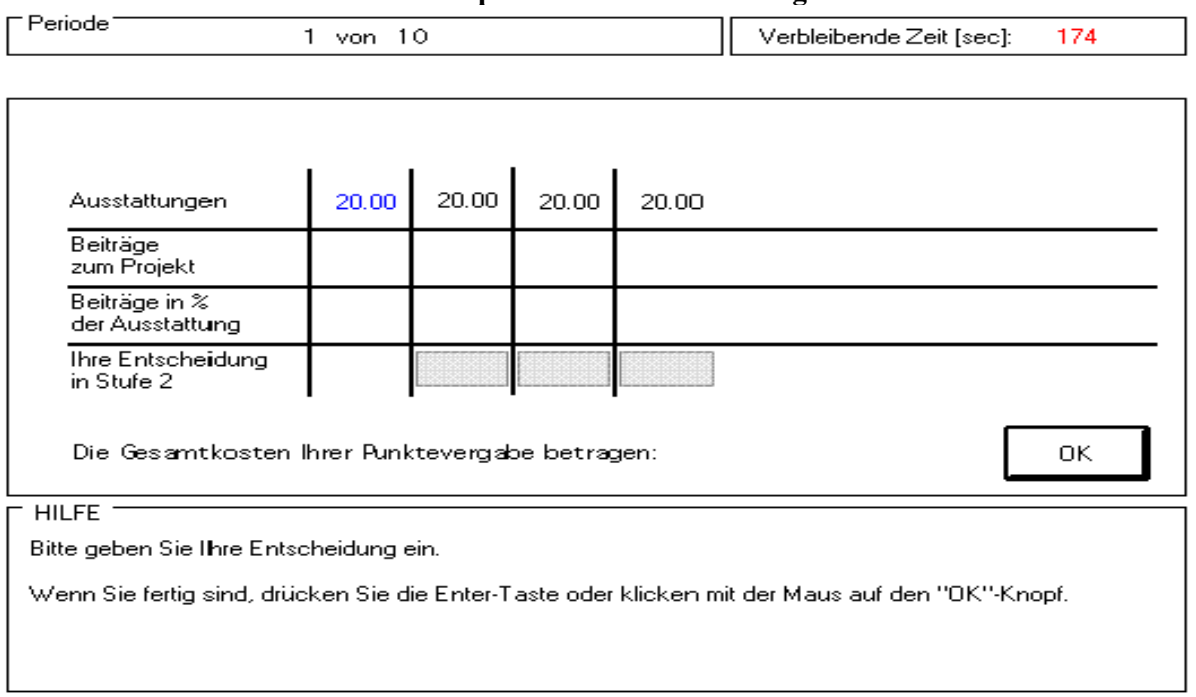

Besides the period and time display, you see here how much each group member contributed to the project at the first stage. Your contribution is displayed in blue in the first column, while the contributions of the other group members of this period are shown in the remaining three columns. Please note that the composition of the groups is renewed in each period. Besides the absolute contributions, the contribution in percent of the endowment is also displayed.

You must now decide how many points to give to each of the other three group members. You must enter a number for each of them. If you do not wish to change the income of a specific group member then you must enter 0 . For your decision you have 180 seconds in the first two periods and 120 seconds in the remaining periods. You can move from one input field to the other by pressing the tab -key $(\rightarrow \mid)$ or by using the mouse.

If you distribute points, you have costs in Guilders which depend on the amount of points you distribute. You can distribute between 0 and 10 points to each group member. The more points you give to any group member, the higher your costs. Your total costs are equal to the sum of the costs of distributing points to each of the other three group members. The following table illustrates the relation between distributed points to each group member and the costs of doing so in Guilders.

\begin{tabular}{|l|l|l|l|l|l|l|l|l|l|l|l|}
\hline points & $\mathbf{0}$ & $\mathbf{1}$ & $\mathbf{2}$ & $\mathbf{3}$ & $\mathbf{4}$ & $\mathbf{5}$ & $\mathbf{6}$ & $\mathbf{7}$ & $\mathbf{8}$ & $\mathbf{9}$ & $\mathbf{1 0}$ \\
\hline costs of these points & 0 & 1 & 2 & 4 & 6 & 9 & 12 & 16 & 20 & 25 & 30 \\
\hline
\end{tabular}

Supposing you give 2 points to one member this costs you 2 Guilders; if you give 9 points to another member this costs you a further 25 Guilders; and if you give the last group member 0 points this has no costs for you. In this case your total costs of distributing points would be 27 Guilders $(2+25+0)$. Your total costs of distributing points are displayed on the input screen. As long as you have not pressed the O.K. button you can revise your decision.

If you choose 0 points for a particular group member, you do not change his or her income. However if you give a member 1 point (by choosing 1) you reduce his or her income from the first stage by 10 percent. If you give a member 2 points (by choosing 2 ) you reduce his or her income by 20 percent, etc. The amount of points you distribute to each member determines therefore how much you reduce their income from the first stage.

Whether or by how much the income from the first stage is totally reduced depends on the total of the received points. If somebody received a total of 3 points (from all other group members in this period) his or her income would be reduced by 30 percent. If somebody received a total of 4 points his or her income would be reduced by 40 percent. If anybody receives 10 or more points their income from the first stage will be reduced by 100 percent. The income from the first stage for this member would in this case be reduced to zero. Your total income from the two stages is therefore calculated as follows: 


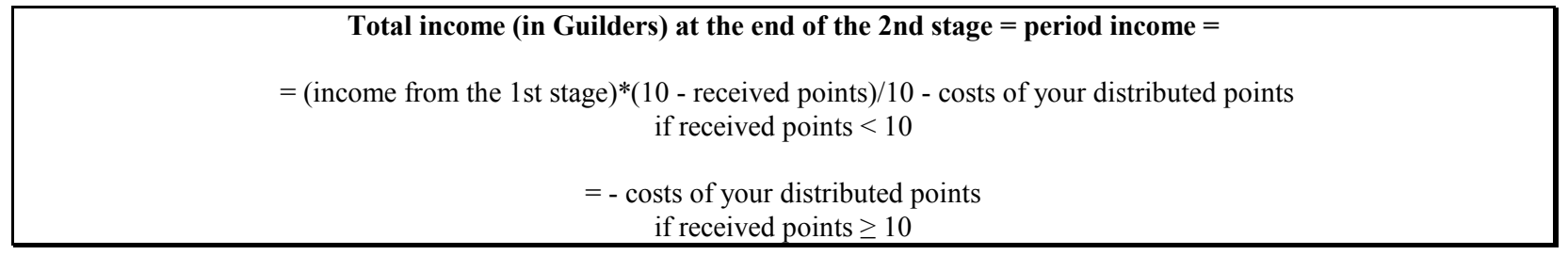

Please note that your income in Guilders at the end of the second stage can be negative, if the costs of your points distributed exceeds your (possibly reduced) income from the first stage. You can however evade such losses with certainty through your own decisions!

After all participants have made their decision, your income from the period will be displayed on the following screen:

The income screen at the end of the 2 nd stage

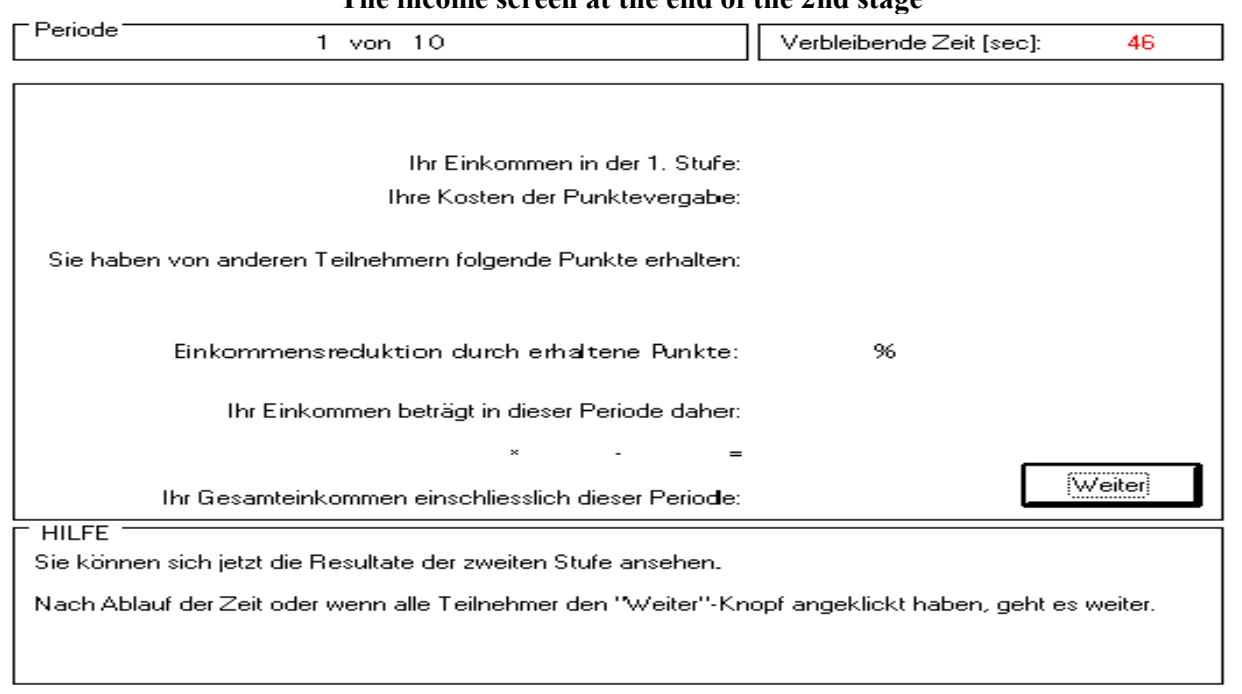

The calculation of your income from the first period, the costs of your distribution of points and your income in the period are as explained above. Do you have any further questions?

\section{Control Questionaire}

1. Each group member has an endowment of 20 points. Nobody (including yourself) contributes any point to the project at the first stage. How high is:

Your income from the first stage?

The income of the other group members from the first stage?

2. Each group member has an endowment of 20 points. You contribute 20 points to the project at the first stage. All other group members each contribute 20 points to the project at the first stage. What is:

Your income from the first stage?...........

The income of the other group members from the first stage?.

3. Each group member has an endowment of 20 points. The other three group members contribute together a total of points to the project.

a) What is your income from the first stage if you contribute a further 0 points to the project?.

b) What is your income from the first stage if you contribute a further 15 points to the project?.

4. Each group member has an endowment of 20 points. You contribute 8 points to the project. 
a) What is your income from the first stage if the other group members together contribute a further total of 7 points to the project?

b) What is your income from the stage if the other group members together contribute a further total of 22 points to the project?

5. At the second stage you distribute the following points to your three other group members: $9,5,0$. What are

the total costs of your distributed points?

6. What are your costs if you distribute a total of 0 points?

7. By how many percent will your income from the first stage be reduced, when you receive a total of 0 points from other group members?.

8. By how many percent will your income from the first stage be reduced, when you receive a total of 4 points from other group members?

9. By how many percent will your income from the first stage be reduced, when you receive a total of 15 points

from the other group members?

\section{After the 10th period, subjects received the following sheet:}

We will now repeat this experiment with one change. As before, the experiment consists of ten periods and in each period you have to make a decsion how many of the 20 tokens at your disposal you want to contribute to the project (and, implicitly, how many you keep for yourself).

\section{The change}

The second stage is removed. In the following ten periods there will be only the 1st stage, which is identical to the first stage before. Your income in Guilders in these second sequence of ten periods will be calculated exactly as before.

After the end of these 10 periods, the whole experiment is definitely finished and you will get:

Your income in guilders from the first set of 10 periods

+ Your income in guilders from the second set of 10 periods

$=$ Total income in Guilders

+15 Swiss Franks show-up fee 